\title{
Energy expenditure in frontotemporal dementia: a behavioural and imaging study
}

\begin{tabular}{|c|c|}
\hline Journal: & Brain \\
\hline Manuscript ID & BRAIN-2016-00843.R1 \\
\hline Manuscript Type: & Original Article \\
\hline Date Submitted by the Author: & $\mathrm{n} / \mathrm{a}$ \\
\hline Complete List of Authors: & $\begin{array}{l}\text { Ahmed, Rebekah; Neuroscience Research Australia, } \\
\text { Landin-Romero, Ramon; Neuroscience Research Australia, } \\
\text { Collett, Tinh-Hai; Institute of Metabolic Science } \\
\text { Van der Klaauw, Agatha; Institute of Metabolic Science } \\
\text { Devenney, Emma; Neuroscience Research Australia, ; University of New } \\
\text { South Wales, } \\
\text { Henning, Elana; University of Cambridge Metabolic Research Laboratories } \\
\text { and NIHR Cambridge Biomedical Research Centre, Wellcome Trust-MRC } \\
\text { Institute of Metabolic Science, } \\
\text { Kiernan, Matthew; University of Sydney, Brain and Mind Research Institute } \\
\text { Piguet, Olivier; Neuroscience Research Australia, } \\
\text { Farooqi, Sadaf; University of Cambridge Metabolic Research Laboratories } \\
\text { and NIHR Cambridge Biomedical Research Centre, Wellcome Trust-MRC } \\
\text { Institute of Metabolic Science, } \\
\text { Hodges, John; Neuroscience Research Australia, }\end{array}$ \\
\hline Subject category: & Dementia \\
\hline $\begin{array}{r}\text { To search keyword list, use } \\
\text { whole or part words followed } \\
\text { by an } * \text { : }\end{array}$ & $\begin{array}{l}\text { Frontotemporal dementia < DEMENTIA, Behavioural neurology < } \\
\text { NEUROPSYCHIATRY, Autonomic nervous system < NEUROMUSCULAR } \\
\text { DISEASES, Amyotrophic lateral sclerosis < NEURODEGENERATION: } \\
\text { CELLULAR AND MOLECULAR, Dementia: structural MR imaging < } \\
\text { DEMENTIA }\end{array}$ \\
\hline
\end{tabular}




\section{Energy expenditure in frontotemporal dementia: a behavioural and imaging study}

Rebekah M Ahmed MBBS, FRACP ${ }^{1,2,3,5}$, Ramon Landin-Romero $\mathrm{PhD}^{1,2,3}$, Tinh-Hai Collet $\mathrm{MD}^{4}$, Agatha A. van der Klaauw MD PhD ${ }^{4}$, Emma Devenney ${ }^{1,2,3,5}$, Elana Henning $\mathrm{BSc}^{4}$, Matthew C. Kiernan $\mathrm{DSc}^{5}$, Olivier Piguet $\mathrm{PhD}^{1,2,3}$, I. Sadaf Farooqi MB.ChB, $\mathrm{PhD}^{4}$, John R Hodges MD, FRCP ${ }^{1,2,3}$.

${ }^{1}$ Neuroscience Research Australia, Sydney, Australia

${ }^{2}$ University of New South Wales, Sydney, Australia

${ }^{3}$ ARC Centre of Excellence in Cognition and its Disorders, the University of New South Wales, Sydney, 2031 Australia

${ }^{4}$ University of Cambridge Metabolic Research Laboratories and NIHR Cambridge Biomedical Research Centre, Wellcome Trust-MRC Institute of Metabolic Science, Addenbrooke's Hospital, Cambridge, United Kingdom

${ }^{5}$ Brain \& Mind Centre, Sydney Medical School, University of Sydney, 2000, Australia

\section{Corresponding Author}

Dr Rebekah Ahmed and Professor John Hodges

Neuroscience Research Australia,

Barker St, Randwick

NSW 2031, Australia

Phone: +61 293991000 Fax: +61293991646

E-mail: rebekahahmed@gmail.com and j.hodges@neura.edu.au

Abstract word count: 326

Word count: $\mathbf{5 9 3 5}$

References: 72

Figures: 5

Tables: 4

Supplementary files: 3

Key words: Frontotemporal dementia, metabolism, heart rate, physiology, autonomic function. 


\begin{abstract}
Abnormal eating behaviour and metabolic parameters including insulin resistance, dyslipidaemia and body mass index are increasingly recognized as important components of neurodegenerative disease and may contribute to survival. It has previously been established that behavioural variant frontotemporal dementia is associated with abnormal eating behaviour characterised by increased sweet preference. In this study, it was hypothesized that behavioural variant frontotemporal dementia might also be associated with altered energy expenditure. A cohort of 19 patients with behavioural variant frontotemporal dementia, 13 with Alzheimer's disease and 16 (age- and sex- matched) healthy controls were studied using Actiheart devices (CamNtech, UK) to assess resting and stressed heart rate. Actiheart devices were fitted for 7 days to measure sleeping heart rate, activity levels, and resting, active and total energy expenditure. Using high resolution structural MRI the neural correlates of increased resting heart rate were investigated including cortical thickness and region of interest analyses. In behavioural variant frontotemporal dementia, resting $(p=.001)$, stressed $(p=.037)$ and sleeping heart rate $(p=.038)$ were increased compared to controls, and resting heart rate $(p=.020)$ compared to Alzheimer Disease patients. Behavioural variant frontotemporal dementia was associated with decreased activity levels compared to controls $(p=.002)$ and increased resting energy expenditure $(p=.045)$ and total energy expenditure $(p=.035)$. Increased resting heart rate correlated with behavioural (Cambridge Behavioural Inventory) and cognitive measures (Addenbrooke's Cognitive Examination). Increased resting heart rate in behavioural variant frontotemporal dementia correlated with atrophy involving the mesial temporal cortex, insula, and amygdala, regions previously suggested to be involved exclusively in social and emotion processing in frontotemporal dementia. These neural correlates overlap the network involved in eating behaviour in frontotemporal dementia suggesting, a complex interaction between eating behaviour, autonomic function and energy homeostasis. As such the present study suggests that increased heart rate and autonomic changes are prevalent in behavioural variant frontotemporal dementia, and are associated with changes in energy expenditure. An understanding of these changes and neural correlates may have potential relevance to disease progression and prognosis.
\end{abstract}




\section{Introduction}

Traditionally Frontotemporal dementia (FTD) has been viewed as a syndrome characterised by behavioural and cognitive changes, although increasingly it is being recognised that there is involvement of networks that affect physiological processing including somatosensory processing including pain and temperature (Fletcher et al., 2015a; Fletcher et al., 2015b), autonomic processing (Ahmed et al., 2015a; Guo et al., 2016), and neuroendocrine and metabolic changes (Ahmed et al., 2014b; Ahmed et al., 2015b). In behavioural variant frontotemporal dementia (bvFTD), eating behavioural changes are common, including hyperphagia, increased sweet preference and changes in food preference that may be associated with increased body mass index (BMI), dyslipidaemia and insulin resistance (Ahmed et al., 2014b).

In several neurodegenerative diseases it is established that there are changes in metabolic parameters. One such condition is ALS, which shares a clinical and pathological overlap with FTD and where consistent changes have been found (Ahmed et al., 2016b), including increased resting energy expenditure in up to 50\% of patients (Bouteloup et al., 2009; Vaisman et al., 2009). It has also been suggested that the hypermetabolic state (defined as increased energy expenditure) is intrinsically linked to the process of neurodegeneration with several animal models of TDP-43 and the C9ORF72 gene expansion exhibiting hypermetabolism and weight loss (Dupuis et al., 2004; Chiang et al., 2010; Shan et al., 2010; Xu et al., 2010; Koppers et al., 2015).

Given the significant overlap between FTD and ALS at a clinical, pathological and genetic level, it seems plausible that changes in energy expenditure may also be present in FTD (Ahmed et al., 2016b). In addition, the changes in appetite appear to exceed the minor increments in BMI and weight gain seen in bvFTD, suggesting increased energy expenditure may also contribute to the body weight changes seen in patients (Woolley et al., 2007; Ahmed et al., 2014a). This is also suggested by the fact that in studies measuring caloric intake in FTD, BMI does not correlate with caloric intake (Ahmed et al., 2016a). Energy expenditure, which includes basal metabolic rate (amount of energy expended at rest) and active energy expenditure (a combination of activity levels and heart rate), has not been investigated in bvFTD. Intrinsically linked with energy expenditure are potentially alterations in autonomic 
activity including heart rate, heart rate variability, and sympathetic and parasympathetic drive (Messina et al., 2013). Changes in the autonomic nervous system, particularly in the sympathetic nervous system have also been proposed to affect glucose and fat metabolism (Nonogaki, 2000; Penicaud et al., 2000). Increases in heart rate have been found to predict an increase in metabolic rate and energy expenditure, via an increase in circulatory rate and oxygen consumptions (Berggren and Hohwu Christensen, 1950).

Measurement of energy expenditure in free-living individuals is challenging. In this study, we used digital heart rate/activity monitoring (Brage et al., 2004; Brage et al., 2005; Crouter et al., 2008) to examine changes in heart rate (rest, stressed and sleep), activity levels and energy expenditure and the potential correlations that this has to autonomic function in a large group of bvFTD patients, compared to a disease comparison group (Alzheimer's disease, AD) and healthy controls. This approach has been used previously in genetic obesity research but not in patients with neurodegeneration (Pearce et al., 2013). The potential neurobiological underpinnings of increases in heart rate were further examined using structural MRI imaging to provide insight into the neural correlates controlling energy expenditure and autonomic function in FTD. 


\section{Methods}

\section{Participants}

Thirty-two patients with dementia (19 bvFTD, 13 AD) were recruited from Forefront, Neuroscience Research Australia. These individuals were compared with 16 age- and sex-matched healthy controls. All patients underwent neurological review, cognitive assessment and met current clinical diagnostic criteria for probable bvFTD or AD (McKhann et al., 2001; Gorno-Tempini et al., 2011; McKhann et al., 2011; Rascovsky et al., 2011). Disease severity was established using the Frontal Rating Scale (FRS) (Mioshi et al., 2010). Controls were recruited from the Neuroscience Research Australia Volunteer database. Healthy controls scored above 88/100 on the Addenbrooke's Cognitive Examination-III (Hsieh et al., 2013) and 0 on the sum of boxes score of the Clinical Dementia Rating scale (Morris, 1993). Exclusion criteria for patients and controls included concurrent psychiatric disturbance, other neurodegenerative conditions or neurological disorders and/or history of substance abuse.

\section{Patient medical history and medications}

Patients medical records and list of medications were obtained from their general practitioner. Given that the study measured heart rate variations, patients with a known cardiac rhythm disorder e.g. atrial fibrillation, supraventricular tachycardia or conduction delays were excluded from the study (1 bvFTD and 1 AD patient). Patients, their carers and controls were asked about their current smoking status and alcohol intake.

\section{Ethics}

This study was approved by the South Eastern Sydney Local Health District and the University of New South Wales human ethics committees. Written informed consent was obtained from each participant and/or their primary caregiver.

\section{Physiological measurements: Actiheart device}

Participants were fitted with the Actiheart device (CamNtech, Cambridge, UK) a compact device designed to quantify heart rate, activity and energy expenditure 
(Brage et al., 2004; Brage et al., 2005; Crouter et al., 2008). The Actiheart has two clips which are attached directly to standard ECG electrodes. One electrode was attached to $\mathrm{V} 1$ on the chest ( $4^{\text {th }}$ right intercostal space) and the second electrode was placed $10 \mathrm{~cm}$ away on the left mid-clavicular line. The number of $\mathrm{R}$ waves detected is recorded at 15 -second epochs and from this the heart rate is derived. An internal triaxial accelerometer senses the frequency and intensity of the participant's torso movements including walking and pacing from which activity counts are derived. When placed in short term mode, the Actiheart measures heart rate variability, heart rate and inter-beat interval (IBI) of the heart rate, with an epoch length of 15 seconds. Long term recordings in long term mode provide mean heart rate and activity levels over an epoch of 15 seconds and recordings can be made for up to 11 days (Brage et al., 2004; Brage et al., 2005; Crouter et al., 2008).

\section{Measurement of heart rate}

To measure resting and stressed heart rate participants wore the Actiheart in short term recording mode for a period of 6 hours following a standard protocol, described briefly. After arriving fasted (10 hours) and an initial period of introduction patients were given a set breakfast that measured caloric intake (Ahmed et al., 2016a), no caffeine or tea was included in this breakfast to avoid their chronotropic effects. Participants were then asked to rest in a lounge environment and their resting heart rate was obtained over a period of 30 minutes. Following this, participants were then taken into a room and took part in 2 hours of cognitive testing. The initial 30 minutes of this period was taken as the stressed heart rate. Resting and stressed heart rates and measures of autonomic function were obtained after entering the beat-to-beat RR interval data obtained by the Actiheart into Kubios HRV, an advanced and easy to use software for heart rate variability (HRV) analysis (Tarvainen et al., 2014). The following measures were obtained: the root mean squared of successive differences (RMSSD), which is a measure of vagal control of the heart (DeGiorgio et al., 2010); the low frequency (LF), which corresponds to the $0.10 \mathrm{~Hz}$ slow fluctuations of arterial pressure and reflects sympathetic and parasympathetic tone; the high frequency (HF) which corresponds to $\sim 0.25 \mathrm{~Hz}$ fluctuations and is a measure of respiratory sinus arrhythmias and can be considered an index of vagal modulation; and the LF/HF ratio which is used to indicate balance between sympathetic and parasympathetic tone. 


\section{Long term actiheart recordings}

Following the short term analyses, participants were fitted with the Actiheart in long term mode and asked to wear this at home for 7 days to provide continuous heart rate and activity monitoring. The participants wore the device continuously and were allowed to shower with the device. Carers were given instructions to refit the device if it became loose or was removed. From the long-term recording, sleeping heart rate and activity counts were calculated.

\section{Measurement of sleeping heart rate}

Sleeping heart rate was calculated over a period of 1 night. For each participant, the 1 night was selected from the 7 day long term recording where a period of recording of uninterrupted sleep was obtained, between midnight and 5 am where no activity was detected. From this period, the average sleeping heart rate, minimum and maximum heart rate was calculated for each participant. Investigators were blinded to the patient ID and diagnoses for this selection. .

\section{Measurement of activity over 24 hours}

An average activity count over 24 hours was calculated for each participant. This was obtained by selecting a 24-hour period in the 7 day long-term recording where continuous recording was available for each patient. This was found to be day 2 in each patient as the Actiheart had been firmly attached and had not been removed, which tended to occur as the long term recording proceeded. The average activity counts for each patient over these 24 hours was obtained and expressed as an activity count per 24 hours. Significance levels between group means were examined after correcting for age and sex.

\section{Measurement of energy expenditure}

The Actiheart measures heart rate and activity simultaneously and these data are transferred to the Actiheart software which uses a validated branched model equation (Brage et al., 2004; Brage et al., 2005) to derive active energy expenditure for each epoch using a combination of heart rate and activity. Using the branched model equation, group Cal JAP2007 (CamNtech, Cambridge, UK) measures of daily energy expenditure were calculated for each participant each day for 7 days and an average over this period obtained. The following measures were obtained: Active Energy 
expenditure (AEE) derived from the branched model equation, which includes a combination of heart rate and activity measures; Resting energy expenditure (REE) derived from the Schofield equation, designed to measure basal metabolic rate adjusted for weight (Schofield, 1985); Dietary induced thermogenesis (DIT), estimated as $10 \%$ of total energy expenditure; Total energy expenditure (TEE) = REE+ AEE+ DIT; Physical activity level $(\mathrm{PAL})=$ TEE/REE.

\section{Behavioural measurements}

In addition to measurements of heart rate variability, activity and energy expenditure, changes in eating behaviour were measured using caregiver-based questionnaires: the Appetite and Eating Habits Questionnaire (APEHQ) (Ikeda et al., 2002; Ahmed et al., 2014a) and the Cambridge Behavioural Inventory (CBI) (Bozeat et al., 2000). These surveys were completed on the same day the short term recordings were obtained and were felt to be representative of intake over the proceeding 7 days when the long term recordings were obtained. The APEHQ provides measures of nicotine and alcohol consumption. Height and weight were measured barefoot and body mass index (BMI) calculated (weight in kilograms/height in metres squared).

\section{Imaging}

\section{MRI acquisition and preprocessing}

All participants underwent whole brain structural MRI with a 3 T Phillips scanner using a standard 8-channel head coil. 3D high-resolution turbo field echo T1weighted sequences were acquired with the following parameters: coronal orientation, matrix $256 \times 256$, 200 slices, $1 \mathrm{~mm} 2$ in-plane resolution, slice thickness $1 \mathrm{~mm}$, echo time/repetition time $2.6 / 5.8 \mathrm{~ms}$, flip angle $\alpha=8^{\circ}$. MRI scans were obtained on the same day as the physiological and behavioural assessment.

Before analyses, the two T1 volumes were merged and averaged to increase the signal to noise ratio and the grey matter-white matter contrasts in brain structures.

FreeSurfer software, version 5.3.0 (http://surfer.nmr.mgh.harvard.edu) was used for surface-based cortical processing (Dale et al., 1999; Fischl et al., 1999) using standard methods (Fischl and Dale, 2000). Cortical thickness was smoothed with a $20 \mathrm{~mm}$ fullwidth at half-height Gaussian kernel. This level of blurring kernel was chosen to 
reduce the impact of imperfect alignment between cortices and thereby improve the signal-to-noise ratio (Lerch and Evans, 2005).

In addition, the following subcortical structures were automatically segmented and extracted for both hemispheres: thalamus, caudate, putamen, globus pallidus, hippocampus, amygdala, and nucleus accumbens. For these subcortical structures, measurements from both hemispheres were averaged and adjusted for total intracranial volume, in line with previous methodology (Voevodskaya et al., 2014).

All the resulting images were visually inspected and manually corrected in the event of tissue segmentation errors. One bvFTD patient and 2 healthy controls were excluded due to excessive surface or subcortical segmentation errors. Thus, 18 bvFTD, $13 \mathrm{AD}$ and 14 healthy controls were included in the imaging analyses.

\section{Statistical analyses}

\section{Demographic and physiological variables}

Analyses were conducted using IBM SPSS statistics (version 21.0). KolmogorovSmirnov tests were run to determine suitability of variables for parametric analyses. One-way analyses of variance (ANOVA), followed by Tukey post hoc tests, were used to determine group differences in demographic and clinical variables (age, ACER). Categorical variables were analyzed using chi-square analyses. Independent t-tests were used to determine differences between bvFTD and AD for disease duration, abnormal behaviour (total CBI, CBI behavioural) and eating behaviour (APEHQ, CBI eating, and BMI) ( $p \leq 0.05$ regarded as significant). Measurements of heart rate (resting and stressed), autonomic function (resting and stressed LF, HF, RMSSD after $\log$ transformation), activity counts and energy measures (REE, AEE, DIT, PAL) were also explored using ANOVA, followed by Tukey post hoc tests. The relationship between resting heart rate and disease duration, BMI, eating behaviour (APEHQ total score) cognitive status (ACE-III) and behavioural measures (CBI total, eating and behavioural) were further explored using Pearson rank correlations corrected for multiple comparisons ( $p \leq 0.01$ regarded as significant).

\section{Imaging data analyses}


For cortical thickness, sets of vertex-by-vertex analyses were performed using general linear models aimed to examine differences in cortical thickness between groups and then to estimate the neural correlates for the physiological variables where bvFTD showed significant differences with both $\mathrm{AD}$ and healthy controls (resting heart rate and stressed heart rare). In the first set of analyses, overall cortical thickness of both hemispheres was modelled including cortical thickness as a dependent variable and group (bvFTD, AD, healthy controls) as an independent variable. In the second set of analyses, we created separate linear models, one for each physiological variable under examination. Each model included the following repressors: group (bvFTD, AD, healthy controls), the physiological variable (resting heart rate, stressed heart rare) and the interaction between group and the physiological variable. To determine physiological associations with cortical thickness specific to diagnostic group, we focused on the interaction effect between each diagnosis and each physiological variable. Correlations between physiological variables and cortical thickness were investigated first by combining all participants (behavioural variant FTD, , Alzheimer's disease, controls) and then in each patient group combined with controls, to identify neural correlates of resting and stressed heart rate to each patient group.. Since the groups were matched at baseline for age, sex and duration of disease, no covariates were included in the models. Statistical significance was set at $p=0.001$ uncorrected for multiple comparisons. In addition, we used a conservative cluster extent threshold of $\mathrm{k}>50 \mathrm{~mm}^{2}$. This approach is designed to minimize Type I error while balancing the risk of Type II error (Lieberman and Cunningham, 2009). For the subcortical regions, group comparisons of subcortical volumes between bvFTD, AD and healthy controls were performed using ANOVA. Post hoc analyses were corrected for multiple comparisons using a Sidak adjustment. Next, in order to uncover the subcortical grey matter correlates of resting heart rate and stressed heart rate, correlations were investigated using the same approach outlined above. Pearson two-tailed correlational analyses were conducted with Bonferroni correction for multiple comparisons $(p<\propto / k=.007)$.

\section{Region of interest analyses}

In addition to the whole-brain analyses, a set of cortical regions of interest (ROI) were selected and computed and averaged from the regional parcellations provided by FreeSurfer for both hemispheres. These regions were selected according to previous 
findings in the literature examining associations between autonomic function (e.g., pain and temperature and heart rate) and brain regions in bvFTD and AD and normal controls (Critchley et al., 2003; Jones, 2011; Fletcher et al., 2015a). The regions selected included the prefrontal, mesial temporal and anterior cingulate cortices, and the insula. Details on the computation of these measurements can be found in Supplementary Table S1. Pearson two-tailed correlations were used to examine associations between these ROIs and the resting and stressed heart rate. These analyses were Bonferroni corrected to control for multiple comparisons $(p<\propto / k=$ $.0125)$. 


\section{Results}

Participants groups were representative of the diseases studied and did not differ in sex distribution, age or disease duration (Table 1 , all $p$ values $>0.365$ ). Group differences were observed on measures of cognition (ACE-III), behavioural measures and eating behaviour (Table 1) and were in keeping with the known behaviour of the diagnostic groups. On the ACE-III as expected the patient groups scored lower than controls $(p<.001)$. The bvFTD group was more functionally impaired relative to AD (FRS; $\mathrm{t}=3.3, p=.03$ ). The bvFTD group as expected scored higher than the AD group on the total CBI score $(\mathrm{t}=3.6, p=.001)$, and CBI behavioural score $(\mathrm{t}=4.1, p$ $<.001)$.

\section{Medications, smoking and alcohol intake (Table 1)}

As expected, a higher number of AD patients were on cholinesterase inhibitors $(9$ patients) compared to the bvFTD ( 2 patients) and control (no patient) groups. There was no difference in the number of patients treated with a medication likely to affect heart rate and cardiac conduction (e.g. beta blocker, calcium channel blocker) between the groups. One bvFTD patient was on stable and adequate thyroxine treatment. Two bvFTD patients and 2 control subjects were current smokers. Eight bvFTD patients carers reported that they consumed alcohol normally, less than weekly in 4 and several times per week in 4 . Ten control subjects reported alcohol consumption, 4 less than weekly and 6 several times a week. Five AD patients reported alcohol intake regularly, 2 several times a week and 3 less than weekly. No patient or control participant stated that they consumed more alcohol than the recommended amount by the Australian National Health and Medical research council.

\section{Eating behaviour and BMI}

On both the APEHQ and CBI eating score the bvFTD group showed more severe eating disturbance based on caregiver surveys compared with $\mathrm{AD}(\mathrm{t}=4.1, p<.001)$. The bvFTD group had an increased BMI (Figure 1) compared to the $\operatorname{AD}(p=.001)$ and Control groups $(p=.008)$ (Table 1).

[INSERT FIGURE 1 HERE] 


\section{Heart rate and autonomic function}

Significant group differences were present for both resting $(\mathrm{F}=8.6, p=.001)$ and stressed $(\mathrm{F}=3.2, p=.047)$ heart rate measures. The bvFTD group (mean $=81.8 \mathrm{bpm}$ had an increased resting heart rate compared to both the control (mean=68.5 $p=$ $.001)$ and $\mathrm{AD}$ groups $($ mean $=72.5, p=.020)$ and an increased stressed heart rate compared to the control group $(\mathrm{bvFTD}=81.5, \mathrm{AD}=76.1$, Control $=71.9 ; p=.037$ ) (Figure 2). On measures of autonomic function (Table 2), no significant group differences were detected; however, a trend for the bvFTD group to have a decreased RMSSD value, in both resting $(\mathrm{p}=.076)$ and stressed states $(\mathrm{p}=.063)$ was present

[INSERT FIGURE 2 HERE]

\section{Correlations of resting heart rate with behavioural measures}

When all groups were combined, resting heart rate was positively correlated with behavioural and eating changes as reflected by the CBI total $(r=.417, p=.004)$, CBI behavioural $(r=.451, p=.001)$, and total CBI eating score $(r=.307, p=.01)$, and negatively correlated with cognitive function on the ACE-III $(r=-.314, p=.01)$, functional ability on the FRS $(r=-.308, p=.05)$. As in prior studies, an increased BMI correlated with behavioural changes on the CBI total $(r=.369, p=.01), \mathrm{CBI}$ behavioural $(r=.334, p=.01)$, and total CBI eating score $(r=.397, p=.006)$, and the APEHQ $(r=.461, p=.01)$. BMI did not correlate with resting heart rate $(r=$ $.206, p=.160)$.

\section{Long term actiheart recordings}

Long-term recordings over 7 days were obtained for 12 bvFTD, $10 \mathrm{AD}$, and 11 control participants to measure sleeping heart rate and activity levels. Several bvFTD patients refused to wear the Actiheart or when at home disposed of it. The patients in the subset analyses did not differ from the larger group in which short term recordings and imaging correlation were conducted.

\section{Sleeping heart rate}

As with resting and stressed heart rate significant group differences were also detected in mean sleeping heart rate (Figure 3a) $(\mathrm{F}=3.9, p=.032)$ with the bvFTD 
group (mean $=71.6 \mathrm{bpm}$ ) having an increased sleeping heart rate compared to the control group $($ mean $=61.5 \mathrm{p}=.038)$ and a trend compared to the $\mathrm{AD}$ group $(\mathrm{mean}=$ $62.8 \mathrm{p}=.085)$. No group differences $(\mathrm{F}=1.4 p=.270)$ in mean minimum heart rate were detected between the bvFTD $(58.9 \pm 7.3 \mathrm{bpm}), \mathrm{AD}(54.7 \pm 8.2)$ and control groups $(55.1 \pm 5.2)$. By contrast, the bvFTD group (100.2 \pm 13.9$)$ had an increased maximum heart rate compared to the control group $(95.7 \pm 14.3 \mathrm{bpm} ; \mathrm{F}=4.2 \mathrm{p}=$ $.025)$.

\section{Activity levels}

Group differences were detected on activity counts (Figure $3 b$ ) over a 24 hour period, after correcting for age and sex. Contrary to what was expected both the bvFTD ( $p=$ $.002)$ and $\mathrm{AD}$ groups $(p=.05)$ showed significantly decreased activity counts per hour compared with the controls, suggesting particularly that the bvFTD group has reduced activity levels.

\section{[INSERT FIGURE 3 HERE]}

\section{Energy expenditure}

On examination of energy expenditure group differences were present (Table 3), with the bvFTD group having an increased resting energy expenditure compared to the control $(\mathrm{p}=.045)$ and AD $(\mathrm{p}=.005)$ groups. The bvFTD group also had an increased diet induced thermogenesis and total energy expenditure compared to the other groups. Despite the finding of decreased activity counts in bvFTD, no significant group differences in active energy expenditure were observed (calculated as a combination of heart rate and activity levels), suggesting that the decreased activity counts in bvFTD may not have affected the active energy expenditure, due to the increased heart rate seen in this group.

\section{Imaging analyses}

\section{Atrophy analyses}

Group comparisons between each clinical group and controls revealed the characteristic profiles of brain atrophy previously reported as consistent with a diagnoses of bvFTD and AD. These results are presented in Supplementary Figure S1 
and Supplementary Table S2. In brief, bvFTD patients showed atrophy in the insula and inferior frontal and anterior temporal cortices. In contrast, AD patients demonstrated widespread and bilateral atrophy involving parietal, temporal and to a lesser extent frontal regions, compared with controls. In addition, both clinical groups showed atrophy in all subcortical structures measured compared with controls, with the exception of the thalamus and the globus pallidus (Supplementary Table S2). The amount of atrophy in these structures was of similar magnitude in bvFTD and AD.

\section{Neural correlates of resting and stressed heart rate}

Unbiased whole brain analyses yielded a significant association between increasing resting heart rate and cortical thinning in the right posterior cingulate and right inferior parietal cortex when combining bvFTD and AD patients together (Figure 4).

[INSERT FIGURE 4 HERE]

In bvFTD but not in $\mathrm{AD}$, increased resting heart rate was associated with volume reductions in the thalamus $(r=-.349, p=.05)$, caudate $(r=-.334, p=.06)$, putamen $(r$ $=-.342, p=.05)$, hippocampus $(r=-.529, p=.002)$, amygdala $(r=-.353, p=.04)$ and nucleus accumbens $(r=-.446, p=.01)$, structures which are known in normal controls to be involved in autonomic regulation. Of these correlations, only the association between reduced hippocampal volume and increased resting heart rate survived conservative Bonferroni correction for multiple comparisons (Table 4).

\section{[INSERT TABLE 4 HERE]}

Also in bvFTD but not in AD, ROI analyses uncovered significant associations between increased resting heart rate and cortical thinning in the mesial temporal cortex $(r=-.520, p=.002)$ and the insula $(r=-.490, p=.004)$. Additional correlations were also found with the prefrontal $(r=-.359, p=.04)$ and anterior cingulate cortices $(r=-.352, p=.04)$, again structures known to be integral to autonomic control, although these did not survive correction for multiple comparisons (Figure 5).

\section{[INSERT FIGURE 5 HERE]}


No further significant associations were found between stressed heart rate and cortical or subcortical regions in either bvFTD or AD.

\section{Discussion}

Behavioural variant frontotemporal dementia is characterized by an increased resting, stressed and sleeping heart rate compared to both $\mathrm{AD}$ and healthy controls. Given that changes in heart rate are indicative of changes in metabolic rate and energy expenditure (Berggren and Hohwu Christensen, 1950; Penzel et al., 2003), via the relationship between pulse rate, circulation and oxygen consumption, these changes suggest the presence of a hypermetabolic state in bvFTD. Behavioural variant frontotemporal dementia is also characterised by increased resting energy expenditure, total energy expenditure and decreased activity levels.. Changes in heart rate correlate to a neural network involving the mesial temporal cortex, insula, nucleaus accumbens and cingulate.

In ALS, which overlaps clinically, pathologically and genetically with bvFTD, changes in heart rate (Chida et al., 1989) and a state of hypermetabolism (Desport et al., 2001) have also been documented, with an increased heart rate on formal autonomic function testing being found secondary to increased sympathetic and decreased parasympathetic input (Chida et al., 1989). In the present study, indications of decreased vagal tone and parasympathetic input in bvFTD were also present, with a trend towards decreased RMSSD, which is a measure of heart rate variability and reflects the integrity of vagus nerve mediated control of the heart (DeGiorgio et al., 2010). There is good experimental evidence in rodents and humans that changes in autonomic tone induced directly or indirectly (for example through thyroid disorders) affect energy expenditure and peripheral metabolism (lipolysis) (Nonogaki, 2000; Penicaud et al., 2000; Messina et al., 2013). It is therefore readily plausible that changes in heart rate may alter energy expenditure in patients with FTD. However, this remains to be established in studies using indirect calorimetry although we note these can be quite challenging in patients with complex behavioural problems. 
Anecdotally, patients with bvFTD are described as being restless with pacing behaviour or alternatively to show inertia (Piguet et al., 2009), but activity levels have not been systematically examined. It has also been suggested that bvFTD patients may not show the degree of weight gain expected in the setting of their increased eating due to hyperactivity (Woolley et al., 2007). Here, however, we have demonstrated that bvFTD patients show decreased activity levels compared with healthy controls. This decreased activity may be secondary to the increased apathy seen in this disorder, which has been, related to atrophy in the right caudate, ventral striatum and cortical basal ganglia circuits (Eslinger et al., 2012), brain regions commonly affected in bvFTD.

In addition, bvFTD patients exhibited an increased resting energy expenditure (REE), a measure of the resting metabolic rate, and total energy expenditure. The increased REE and basal metabolic state may in part be explained by the increased body mass index seen in the bvFTD group, but may also be influenced by the presence of a hypermetabolic state. This finding is in keeping with results in ALS showing that ALS patients may show total energy expenditure well above their REE and activity levels and potentially secondary to hypermetabolism (Kasarskis et al., 2014).

Increased resting heart rate was also found to correlate with increasing cognitive impairment (lower ACE-III scores) and increasing behavioural impairment (higher CBI scores). Changes in neurodegeneration have been linked to alterations in energy homeostasis with animal models of ALS and FTD associated with weight loss and hypermetabolism (Dupuis et al., 2004; Chiang et al., 2010; Shan et al., 2010; Xu et al., 2010). Additional studies in patients with the language variants of FTD, particularly Semantic dementia may be informative. It is suspected that there may well be changes in energy expenditure in semantic dementia given that they have similar changes in BMI to bvFTD in the contenxt of eating behavioural changes (Ahmed et al 2014) and a similar pathology to ALS (TDP-43), where energy changes are prominent (Dupuis et al., 2011; Ahmed et al., 2016b).

It may be suggested that the changes seen in heart rate in bvFTD i.e. an increased resting and stressed and sleeping heart may be secondary to environmental factors such as caffeine, nicotine or alcohol consumption. This seems unlikely given that 
there was no difference in reported smoking frequency and alcohol consumption between the groups, with only 2 bvFTD and 2 control subjects reported to be smokers, and similar rates of reported regular alcohol consumption, which were within recommended national guidelines. It is also unlikely that caffeine and tea intake would have affected the short term heart rate recordings (resting and stressed heart rate) as patients attended fasted and then received a breakfast with no caffeine available. Caffeine and tea intake was not measured during the long term measurements and this could potentially confound the long term recordings, however this is unlikely given that resting heart was elevated in the setting of the controlled environment of no caffeine consumption for the short term recordings. .When considering these results, it should be noted that changes in heart rate may potentially be related to decreased physical fitness associated with increasing disease severity, decreased activity secondary to apathy or loss of independence. However as increases in heart rate did not correlate with BMI changes, this suggests that changes in heart rate are far more complex than just being related to physical fitness and likely represent a complex interaction between atrophy in key cortical areas affecting autonomic function, and energy expenditure, and are likely to be centrally rather than peripherally mediated.

Whilst medications that potentially affect heart rate may affect the results of our study, there was no significant difference in use of chronotropic drugs between the groups. Cholinesterase inhibitor treatment has been linked with bradycardia in a small proportion of patients (Hernandez et al., 2009). Despite the high number of AD patients on this medication, this is unlikely to be a confounding issue in the current study as the mean resting heart rate in the AD group was above that seen in the normal control population.

In this study, an increased resting heart rate in bvFTD was found to correlate with atrophy of the mesial temporal cortex including hippocampus, together with the amygdala, nucleus accumbens, insula and cingulate, all structures known to be integral to autonomic control of the human body and involving the limbic system, which is known to be involved in FTD (Seeley et al., 2008; Jones, 2011). In bvFTD, pathological changes in these structures have traditionally being linked to disturbance of memory and social cognition (Galton et al., 2001; Kipps et al., 2009; Kumfor et al., 
2013; Irish et al., 2014). Recently decreased cardiac vagal tone has been found in bvFTD and linked to reduced agreeableness and a network involving left-lateralized functional and structural frontoinsular and cingulate cortex deficits (Guo et al., 2016). Our findings suggest that in addition these structures may have a fundamental role in autonomic, energy expenditure and metabolic control in bvFTD.

The anterior cingulate cortex, has been shown to participate in decision making, response selection (Devinsky et al., 1995), anticipation of reward, task reinforcement (Amiez et al., 2006; Rushworth et al., 2007) and in controlling visceromotor, endocrine and skeletomotor outputs (Vogt et al., 1992), potentially via integration of cognitive with autonomic information (Critchley et al., 2001). In healthy individuals, activity of the anterior cingulate cortex has been associated with increased body mass index (Volkow et al., 2009) suggesting a role for this structure in regulating eating and metabolism. It has also been shown that the anterior cingulate cortex is related to sympathetic modulation of heart rate dissociable from cognitive and motor related activity and that focal damage to brain region can result in both an increase and decrease in heart rate (Critchley et al., 2003). Although the cingulate cortex responds to emotional stimuli, it is also metabolically active at rest (Raichle et al., 2001; Luu and Posner, 2003), suggesting a pivotal role for this brain region in the normal physiological control of the body.

Several studies and meta-analyses have shown the integral role that the amygdala plays in controlling heart and heart rate variability, particularly in times of emotional response and threat (Thayer et al., 2012). The fact that the amygdala correlated with increased resting heart rate in bvFTD in the current study, suggests that this structure plays a role in the physiological and metabolic changes seen in bvFTD and not simply in response to emotional stimuli. The insula is involved early in the course of bvFTD (Seeley et al., 2008) and has been found on voxel-based morphometry (VBM) to correlate to pain and temperature symptoms in bvFTD, with the suggestion that it forms a network hub for sensory homeostatic signalling with the thalamus in bvFTD. (Fletcher et al., 2015a). Our findings suggest that the insula also forms an important part of the network involved in heart rate, energy expenditure, autonomic and metabolic control in bvFTD. 
It is of interest that several of the structures found to correlate with increased resting heart rate namely the cingulate cortex, insula and amygdala have been found to correlate with hyperphagia and abnormal eating behaviour in bvFTD. Moreover all of these structures have connections to the hypothalamus (Kullmann et al., 2014; Ahmed et al., 2016a), which has been found to be atrophied in bvFTD and correlate with BMI measures (Ahmed et al., 2015b). This suggests a complex interaction between cortical, subcortical structures and the hypothalamus in the control of eating behaviour, heart rate and energy expenditure all of which are affected in bvFTD.

In $\mathrm{AD}$, by contrast, it has been speculated that weight loss occurs with disease progression and low body weight has previously being correlated to mesial temporal cortex atrophy (Grundman et al., 1996). Further studies using direct measurements of energy intake and expenditure in large numbers of patients and age-and BMI-matched controls (both normal and AD patients) longitudinally are required to assess the relative contributions of these parameters to weight changes in FTD.

Behavioural variant frontotemporal dementia is characterized by an increased resting and sleeping heart rate indicative of changes in metabolic rate and resting energy expenditure which may moderate the weight gain in the setting of prominent changes of eating behaviour. BvFTD is also accompanied by decreased activity levels suggesting that energy expenditure changes are likely secondary to intrinsic processes, driven by changes in heart rate, rather than by an increase in activity levels. Changes in heart rate correlated with atrophy of cingulate and limbic systems including the insula and amygdala, which overlap with networks known to control eating behaviour in bvFTD. Further studies are required to document changes in heart rate and energy expenditure across the ALS-FTD spectrum and in presymptomatic genetic cohorts, to ascertain when changes first develop during the course of the disease. An approach combining longitudinal clinical studies and animal models of FTD and ALS will prove crucial. The current study is the first study to measure the interaction between heart rate, autonomic function and energy expenditure in FTD, using methods from obesity research that allow for measurements over both short term and long term ( 7 days) in the patient's normal environment. Further studies using indirect calorimetry to measure basal metabolic rate and total energy expenditure are warranted to further examine these interactions. An understanding of 
the potential changes in energy expenditure, autonomic function and their neural correlates including involvement of the mesial temporal cortex, cingulate cortex, amygdala and insula in energy expenditure aids in the physiological phenotyping of FTD and extends our knowledge of the disease beyond cognition and emotion processing.

Funding: This work was supported by funding to Forefront, a collaborative research group dedicated to the study of frontotemporal dementia and motor neurone disease, from the National Health and Medical Research Council of Australia (NHMRC) program grant (\#1037746 to MK and JH) and the Australian Research Council Centre of Excellence in Cognition and its Disorders Memory Node (\#CE110001021 to OP and $\mathrm{JH}$ ) and other grants/sources (NHMRC project grant \#1003139). We are grateful to the research participants involved with the ForeFront research studies. RA is a Royal Australasian College of Physicians PhD scholar and MND Australia PhD scholar. OP is an NHMRC Career Development Research Fellow (\#1022684). ISF is supported by the Wellcome Trust, Medical Research Council, European Research Council, NIHR Cambridge Biomedical Research Centre and The Bernard Wolfe Endowment. AAvdK is supported by the Wellcome Trust. THC is supported by research grants from the Swiss National Science Foundation (PBLAP3-145870, P3SMP3-155318).

Author disclosures: The authors declare no competing financial interests

Author contributions:

Rebekah Ahmed: study concept, data analyses, manuscript preparation and writing. Ramon Landin-Romero: data analyses, manuscript preparation and writing. Tinh-Hai Collet: data analyses, manuscript preparation and writing. Agatha van der Klaauw: data analyses, manuscript preparation and writing Emma Devenney: data analyses, manuscript preparation and writing Elana Henning: data analyses, manuscript preparation and writing. Matthew C Kiernan: data analyses, manuscript preparation and writing. Olivier Piguet: data analyses, manuscript preparation and writing. Sadaf Farooqi: study concept, data analyses, manuscript preparation and writing. John Hodges: study concept, data analyses, manuscript preparation and writing. 


\section{References}

Ahmed RM, Irish M, Kam J, van Keizerswaard J, Bartley L, Samaras K, Hodges JR, Piguet O. Quantifying the eating abnormalities in frontotemporal dementia. JAMA Neurol 2014a; 71: 1540-6.

Ahmed RM, MacMillan M, Bartley L, Halliday GM, Kiernan MC, Hodges JR, Piguet 0 . Systemic metabolism in frontotemporal dementia. Neurology $2014 \mathrm{~b}$; 83: 1812-8.

Ahmed RM, Iodice V, Daveson N, Kiernan MC, Piguet O, Hodges JR. Autonomic dysregulation in frontotemporal dementia. J Neurol Neurosurg Psychiatry 2015a; 86: 1048-9.

Ahmed RM, Latheef S, Bartley L, Irish M, Halliday GM, Kiernan MC, Hodges JR, Piguet O. Eating behavior in frontotemporal dementia: Peripheral hormones vs hypothalamic pathology. Neurology 2015b; 85: 1310-7.

Ahmed RM, Irish M, Henning E, Dermody N, Bartley L, Kiernan MC, Piguet O, Farooqi S, Hodges JR. Assessment of Eating Behavior Disturbance and Associated Neural Networks in Frontotemporal Dementia. JAMA Neurol 2016a; 73: 282-90.

Ahmed RM, Irish M, Piguet O, Halliday GM, Ittner LM, Farooqi S, Hodges JR, Kiernan MC. Amyotrophic lateral sclerosis and frontotemporal dementia: distinct and overlapping changes in eating behaviour and metabolism. Lancet Neurol 2016b; 15: 332-42.

Amiez C, Joseph JP, Procyk E. Reward encoding in the monkey anterior cingulate cortex. Cereb Cortex 2006; 16: 1040-55.

Berggren G, Hohwu Christensen E. Heart rate and body temperature as indices of metabolic rate during work. Arbeitsphysiologie 1950; 14: 255-60.

Bouteloup C, Desport JC, Clavelou P, Guy N, Derumeaux-Burel H, Ferrier A, Couratier P. Hypermetabolism in ALS patients: an early and persistent phenomenon. J Neurol 2009; 256: 1236-42.

Bozeat S, Gregory CA, Ralph MA, Hodges JR. Which neuropsychiatric and behavioural features distinguish frontal and temporal variants of frontotemporal dementia from Alzheimer's disease? J Neurol Neurosurg Psychiatry 2000; 69: 178-86.

Brage S, Brage N, Franks PW, Ekelund U, Wong MY, Andersen LB, Froberg K, Wareham NJ. Branched equation modeling of simultaneous accelerometry and heart rate monitoring improves estimate of directly measured physical activity energy expenditure. J Appl Physiol (1985) 2004; 96: 34351.

Brage S, Brage N, Franks PW, Ekelund U, Wareham NJ. Reliability and validity of the combined heart rate and movement sensor Actiheart. Eur J Clin Nutr 2005; 59: 561-70.

Chiang PM, Ling J, Jeong YH, Price DL, Aja SM, Wong PC. Deletion of TDP-43 down-regulates Tbc1d1, a gene linked to obesity, and alters body fat metabolism. Proc Natl Acad Sci U S A 2010; 107: 16320-4.

Chida K, Sakamaki S, Takasu T. Alteration in autonomic function and cardiovascular regulation in amyotrophic lateral sclerosis. J Neurol 1989; 236: $127-30$.

Critchley HD, Mathias CJ, Dolan RJ. Neural activity in the human brain relating to uncertainty and arousal during anticipation. Neuron 2001; 29: 537-45. 
Critchley HD, Mathias CJ, Josephs O, O'Doherty J, Zanini S, Dewar BK, Cipolotti L, Shallice T, Dolan RJ. Human cingulate cortex and autonomic control: converging neuroimaging and clinical evidence. Brain 2003; 126: 213952.

Crouter SE, Churilla JR, Bassett DR, Jr. Accuracy of the Actiheart for the assessment of energy expenditure in adults. Eur J Clin Nutr 2008; 62: 70411.

Dale AM, Fischl B, Sereno MI. Cortical surface-based analysis. I. Segmentation and surface reconstruction. Neuroimage 1999; 9: 179-94.

DeGiorgio CM, Miller P, Meymandi S, Chin A, Epps J, Gordon S, Gornbein J, Harper RM. RMSSD, a measure of vagus-mediated heart rate variability, is associated with risk factors for SUDEP: the SUDEP-7 Inventory. Epilepsy Behav 2010; 19: 78-81.

Desport JC, Preux PM, Magy L, Boirie Y, Vallat JM, Beaufrere B, Couratier P. Factors correlated with hypermetabolism in patients with amyotrophic lateral sclerosis. Am J Clin Nutr 2001; 74: 328-34.

Devinsky 0, Morrell MJ, Vogt BA. Contributions of anterior cingulate cortex to behaviour. Brain 1995; 118 ( Pt 1): 279-306.

Dupuis L, Oudart H, Rene F, Gonzalez de Aguilar JL, Loeffler JP. Evidence for defective energy homeostasis in amyotrophic lateral sclerosis: benefit of a high-energy diet in a transgenic mouse model. Proc Natl Acad Sci U S A 2004; 101: 11159-64.

Dupuis L, Pradat PF, Ludolph AC, Loeffler JP. Energy metabolism in amyotrophic lateral sclerosis. Lancet Neurol 2011; 10: 75-82.

Eslinger PJ, Moore P, Antani S, Anderson C, Grossman M. Apathy in frontotemporal dementia: behavioral and neuroimaging correlates. Behav Neurol 2012; 25: 127-36.

Fischl B, Sereno MI, Dale AM. Cortical surface-based analysis. II: Inflation, flattening, and a surface-based coordinate system. Neuroimage 1999; 9: 195-207.

Fischl B, Dale AM. Measuring the thickness of the human cerebral cortex from magnetic resonance images. Proc Natl Acad Sci U S A 2000; 97: 11050-5.

Fletcher PD, Downey LE, Golden HL, Clark CN, Slattery CF, Paterson RW, Rohrer JD, Schott JM, Rossor MN, Warren JD. Pain and temperature processing in dementia: a clinical and neuroanatomical analysis. Brain 2015a; 138: 3360-72.

Fletcher PD, Nicholas JM, Shakespeare TJ, Downey LE, Golden HL, Agustus JL, Clark CN, Mummery CJ, Schott JM, Crutch SJ, Warren JD. Physiological phenotyping of dementias using emotional sounds. Alzheimers Dement (Amst) 2015b; 1: 170-178.

Galton CJ, Gomez-Anson B, Antoun N, Scheltens P, Patterson K, Graves M, Sahakian BJ, Hodges JR. Temporal lobe rating scale: application to Alzheimer's disease and frontotemporal dementia. J Neurol Neurosurg Psychiatry 2001; 70: 165-73.

Gorno-Tempini ML, Hillis AE, Weintraub S, Kertesz A, Mendez M, Cappa SF, Ogar JM, Rohrer JD, Black S, Boeve BF, Manes F, Dronkers NF, Vandenberghe R, Rascovsky K, Patterson K, Miller BL, Knopman DS, Hodges JR, Mesulam $\mathrm{MM}$, Grossman M. Classification of primary progressive aphasia and its variants. Neurology 2011; 76: 1006-14. 
Grundman M, Corey-Bloom J, Jernigan T, Archibald S, Thal LJ. Low body weight in Alzheimer's disease is associated with mesial temporal cortex atrophy. Neurology 1996; 46: 1585-91.

Guo CC, Sturm VE, Zhou J, Gennatas ED, Trujillo AJ, Hua AY, Crawford R, Stables L, Kramer JH, Rankin K, Levenson RW, Rosen HJ, Miller BL, Seeley WW. Dominant hemisphere lateralization of cortical parasympathetic control as revealed by frontotemporal dementia. Proc Natl Acad Sci U S A 2016.

Hernandez RK, Farwell W, Cantor MD, Lawler EV. Cholinesterase inhibitors and incidence of bradycardia in patients with dementia in the veterans affairs new England healthcare system. J Am Geriatr Soc 2009; 57: 1997-2003.

Hsieh S, Schubert S, Hoon C, Mioshi E, Hodges JR. Validation of the Addenbrooke's Cognitive Examination III in frontotemporal dementia and Alzheimer's disease. Dement Geriatr Cogn Disord 2013; 36: 242-50.

Ikeda M, Brown J, Holland AJ, Fukuhara R, Hodges JR. Changes in appetite, food preference, and eating habits in frontotemporal dementia and Alzheimer's disease. J Neurol Neurosurg Psychiatry 2002; 73: 371-6.

Irish M, Piguet 0 , Hodges JR, Hornberger M. Common and unique gray matter correlates of episodic memory dysfunction in frontotemporal dementia and Alzheimer's disease. Hum Brain Mapp 2014; 35: 1422-35.

Jones SE. Imaging for autonomic dysfunction. Cleve Clin J Med 2011; 78 Suppl 1: S69-74.

Kasarskis EJ, Mendiondo MS, Matthews DE, Mitsumoto H, Tandan R, Simmons Z, Bromberg MB, Kryscio RJ, Group ALSNNS. Estimating daily energy expenditure in individuals with amyotrophic lateral sclerosis. Am J Clin Nutr 2014; 99: 792-803.

Kipps CM, Nestor PJ, Acosta-Cabronero J, Arnold R, Hodges JR. Understanding social dysfunction in the behavioural variant of frontotemporal dementia: the role of emotion and sarcasm processing. Brain 2009; 132: 592-603.

Koppers M, Blokhuis AM, Westeneng HJ, Terpstra ML, Zundel CA, Vieira de Sa R, Schellevis RD, Waite AJ, Blake DJ, Veldink JH, van den Berg LH, Pasterkamp RJ. C9orf72 ablation in mice does not cause motor neuron degeneration or motor deficits. Ann Neurol 2015; 78: 426-38.

Kullmann S, Heni M, Linder K, Zipfel S, Haring HU, Veit R, Fritsche A, Preissl H. Resting-state functional connectivity of the human hypothalamus. Hum Brain Mapp 2014; 35: 6088-96.

Kumfor F, Irish M, Hodges JR, Piguet O. Discrete Neural Correlates for the Recognition of Negative Emotions: Insights from Frontotemporal Dementia. PLoS One 2013; 8: e67457.

Lerch JP, Evans AC. Cortical thickness analysis examined through power analysis and a population simulation. Neuroimage 2005; 24: 163-73.

Lieberman MD, Cunningham WA. Type I and Type II error concerns in fMRI research: re-balancing the scale. Soc Cogn Affect Neurosci 2009; 4: 423-8.

Luu P, Posner MI. Anterior cingulate cortex regulation of sympathetic activity. Brain 2003; 126: 2119-20.

McKhann GM, Albert MS, Grossman M, Miller B, Dickson D, Trojanowski JQ, Work Group on Frontotemporal D, Pick's D. Clinical and pathological diagnosis of frontotemporal dementia: report of the Work Group on Frontotemporal Dementia and Pick's Disease. Arch Neurol 2001; 58: 1803-9. 
McKhann GM, Knopman DS, Chertkow H, Hyman BT, Jack CR, Jr., Kawas CH, Klunk WE, Koroshetz WJ, Manly JJ, Mayeux R, Mohs RC, Morris JC, Rossor MN, Scheltens P, Carrillo MC, Thies B, Weintraub S, Phelps CH. The diagnosis of dementia due to Alzheimer's disease: recommendations from the National Institute on Aging-Alzheimer's Association workgroups on diagnostic guidelines for Alzheimer's disease. Alzheimers Dement 2011; 7: 263-9.

Messina G, De Luca V, Viggiano A, Ascione A, Iannaccone T, Chieffi S, Monda M. Autonomic nervous system in the control of energy balance and body weight: personal contributions. Neurol Res Int 2013; 2013: 639280.

Mioshi E, Hsieh S, Savage S, Hornberger M, Hodges JR. Clinical staging and disease progression in frontotemporal dementia. Neurology 2010; 74: 1591-7.

Morris JC. The Clinical Dementia Rating (CDR): current version and scoring rules. Neurology 1993; 43: 2412-4.

Nonogaki K. New insights into sympathetic regulation of glucose and fat metabolism. Diabetologia 2000; 43: 533-49.

Pearce LR, Atanassova N, Banton MC, Bottomley B, van der Klaauw AA, Revelli JP, Hendricks A, Keogh JM, Henning E, Doree D, Jeter-Jones S, Garg S, Bochukova EG, Bounds R, Ashford S, Gayton E, Hindmarsh PC, Shield JP, Crowne E, Barford D, Wareham NJ, consortium UK, O'Rahilly S, Murphy MP, Powell DR, Barroso I, Farooqi IS. KSR2 mutations are associated with obesity, insulin resistance, and impaired cellular fuel oxidation. Cell 2013; 155: 765-77.

Penicaud L, Cousin B, Leloup C, Lorsignol A, Casteilla L. The autonomic nervous system, adipose tissue plasticity, and energy balance. Nutrition 2000; 16: 903-8.

Penzel T, Kantelhardt JW, Lo CC, Voigt K, Vogelmeier C. Dynamics of heart rate and sleep stages in normals and patients with sleep apnea. Neuropsychopharmacology 2003; 28 Suppl 1: S48-53.

Piguet 0, Hornberger M, Shelley BP, Kipps CM, Hodges JR. Sensitivity of current criteria for the diagnosis of behavioral variant frontotemporal dementia. Neurology 2009; 72: 732-7.

Raichle ME, MacLeod AM, Snyder AZ, Powers WJ, Gusnard DA, Shulman GL. A default mode of brain function. Proc Natl Acad Sci U S A 2001; 98: 676-82.

Rascovsky K, Hodges JR, Knopman D, Mendez MF, Kramer JH, Neuhaus J, van Swieten JC, Seelaar H, Dopper EG, Onyike CU, Hillis AE, Josephs KA, Boeve BF, Kertesz A, Seeley WW, Rankin KP, Johnson JK, Gorno-Tempini ML, Rosen H, Prioleau-Latham CE, Lee A, Kipps CM, Lillo P, Piguet O, Rohrer JD, Rossor MN, Warren JD, Fox NC, Galasko D, Salmon DP, Black SE, Mesulam M, Weintraub S, Dickerson BC, Diehl-Schmid J, Pasquier F, Deramecourt V, Lebert F, Pijnenburg Y, Chow TW, Manes F, Grafman J, Cappa SF, Freedman M, Grossman M, Miller BL. Sensitivity of revised diagnostic criteria for the behavioural variant of frontotemporal dementia. Brain 2011; 134: 2456-77.

Rushworth MF, Behrens TE, Rudebeck PH, Walton ME. Contrasting roles for cingulate and orbitofrontal cortex in decisions and social behaviour. Trends Cogn Sci 2007; 11: 168-76. 
Schofield WN. Predicting basal metabolic rate, new standards and review of previous work. Hum Nutr Clin Nutr 1985; 39 Suppl 1: 5-41.

Seeley WW, Crawford R, Rascovsky K, Kramer JH, Weiner M, Miller BL, GornoTempini ML. Frontal paralimbic network atrophy in very mild behavioral variant frontotemporal dementia. Arch Neurol 2008; 65: 249-55.

Shan X, Chiang PM, Price DL, Wong PC. Altered distributions of Gemini of coiled bodies and mitochondria in motor neurons of TDP-43 transgenic mice. Proc Natl Acad Sci U S A 2010; 107: 16325-30.

Tarvainen MP, Niskanen JP, Lipponen JA, Ranta-Aho PO, Karjalainen PA. Kubios HRV--heart rate variability analysis software. Comput Methods Programs Biomed 2014; 113: 210-20.

Thayer JF, Ahs F, Fredrikson M, Sollers JJ, 3rd, Wager TD. A meta-analysis of heart rate variability and neuroimaging studies: implications for heart rate variability as a marker of stress and health. Neurosci Biobehav Rev 2012; 36: 747-56.

Vaisman N, Lusaus M, Nefussy B, Niv E, Comaneshter D, Hallack R, Drory VE. Do patients with amyotrophic lateral sclerosis (ALS) have increased energy needs? J Neurol Sci 2009; 279: 26-9.

Voevodskaya O, Simmons A, Nordenskjold R, Kullberg J, Ahlstrom H, Lind L, Wahlund LO, Larsson EM, Westman E, Alzheimer's Disease Neuroimaging I. The effects of intracranial volume adjustment approaches on multiple regional MRI volumes in healthy aging and Alzheimer's disease. Front Aging Neurosci 2014; 6: 264.

Vogt BA, Finch DM, Olson CR. Functional heterogeneity in cingulate cortex: the anterior executive and posterior evaluative regions. Cereb Cortex 1992; 2: 435-43.

Volkow ND, Wang GJ, Telang F, Fowler JS, Goldstein RZ, Alia-Klein N, Logan J, Wong C, Thanos PK, Ma Y, Pradhan K. Inverse association between BMI and prefrontal metabolic activity in healthy adults. Obesity (Silver Spring) 2009; 17: 60-5.

Woolley JD, Gorno-Tempini ML, Seeley WW, Rankin K, Lee SS, Matthews BR, Miller BL. Binge eating is associated with right orbitofrontal-insularstriatal atrophy in frontotemporal dementia. Neurology 2007; 69: 142433.

Xu YF, Gendron TF, Zhang YJ, Lin WL, D'Alton S, Sheng H, Casey MC, Tong J, Knight J, Yu X, Rademakers R, Boylan K, Hutton M, McGowan E, Dickson DW, Lewis J, Petrucelli L. Wild-type human TDP-43 expression causes TDP-43 phosphorylation, mitochondrial aggregation, motor deficits, and early mortality in transgenic mice. J Neurosci 2010; 30: 10851-9. 


\section{Figure Legends}

Figure 1: Scatter plot showing BMI values in bvFTD, AD and healthy controls Horizontal line represents mean $+/-$ SD. bvFTD $>$ AD and controls $(p<.001)$

Figure 2. Resting and stressed heart rate in bvFTD, AD and healthy controls $*$ bvFTD $>\operatorname{AD}(p=.028), * *$ bvFTD $>$ Controls $(p=.037), * * *$ bvFTD $>$ Controls $(p=$ $.001)$

\section{Figure 3. Long term Actiheart results}

Mean sleeping heart rate. $* * *$ bvFTD $>$ controls $(\mathrm{p}=.038)$; B) Mean activity counts per 24 hours. $* \mathrm{AD}<$ Controls $(p=.05), * *$ bvFTD $<$ Controls $(p=.002)$

Figure 4. Regions showing significant correlations between cortical thinning and increasing resting heart rate in bvFTD and $\mathrm{AD}$ in whole brain imaging analyses. Statistical significance was set at $\mathrm{p}<.001$ uncorrected for multiple comparisons. bvFTD = behavioural-variant frontotemporal dementia; $\mathrm{AD}=$ Alzheimer's disease.

Figure 5. Significant associations between cortical thickness in preselected ROIs and resting heart rate in bvFTD and HC. No significant associations were seen in AD and HC. Statistical significance was set at $p<.0125$ Bonferroni corrected for multiple comparisons. bvFTD = behavioural-variant frontotemporal dementia; $\mathrm{HC}=$ Healthy controls

Supplementary Figure S1. Patterns of atrophy in bvFTD and AD versus healthy controls. Blue coloured regions show significant cortical thinning in the patient groups compared to controls ( $\mathrm{p}<.05$ FDR corrected). Red coloured regions show 
significantly increased cortical thickness in the patient group compared to controls ( $p$ $<.05$ FDR corrected). 
Table 1. Demographics and clinical characteristics in bvFTD, AD and healthy controls

\begin{tabular}{|c|c|c|c|c|c|c|}
\hline & $\begin{array}{l}\text { bvFTD } \\
(n=19)\end{array}$ & $\begin{array}{c}\text { AD } \\
(n=13)\end{array}$ & $\begin{array}{c}\text { HC } \\
(n=16)\end{array}$ & F value & $p$ value & Post hoc \\
\hline $\operatorname{Sex}(F: M)$ & $8: 11$ & $7: 6$ & $6: 10$ & $.83^{\dagger}$ & ns & - \\
\hline Age (years) & $62 \pm 6.7$ & $66 \pm 8.2$ & $65 \pm 7.7$ & 1.1 & ns & - \\
\hline BMI $\left(\mathrm{kg} / \mathrm{m}^{2}\right)$ & $31.0 \pm 6.9$ & $23.6 \pm 3.1$ & $27.2 \pm 5.9$ & 9.6 & $p<.001$ & bvFTD $>$ AD, HC \\
\hline FRS Rasch score ${ }^{\wedge}$ & $-1.7 \pm 1.2$ & $-.02 \pm 1.4$ & - & $17.7 \#$ & $p<.01$ & bvFTD $<$ AD \\
\hline APEHQ Total & $68.9 \pm 38.6$ & $15.1 \pm 20.2$ & - & $4.1 \#$ & $p<.001$ & bvFTD $>$ AD \\
\hline CBI Total & $86.3 \pm 24.7$ & $51.3 \pm 27.3$ & - & $3.6 \#$ & $p<.01$ & bvFTD $>$ AD \\
\hline CBI eating Total & $9.3 \pm 3.8$ & $3.2 \pm 4.5$ & - & $4.1 \#$ & $p<.001$ & bvFTD $>$ AD \\
\hline Current smokers (n) & 2 & 0 & 2 & $1.7^{\dagger}$ & ns & - \\
\hline Alcohol consumption (n) & 8 & 5 & 10 & $2.1^{\dagger}$ & ns & - \\
\hline
\end{tabular}


Values are expressed as mean \pm standard deviation. bvFTD = behavioural-variant frontotemporal dementia; $\mathrm{AD}=\mathrm{Alzheimer}$ 's disease; $\mathrm{HC}=$ healthy controls; BMI = body mass index; ACE-III = Addenbrooke's Cognitive Examination-III; FRS = Frontotemporal dementia Rating Scale; $\mathrm{APEHQ}=$ Appetite and Eating Habits Questionnaire; CBI = Cambridge Behavioural Inventory; ns = not significant. ${ }^{\dagger}$ Chi-square test; \# t-value; ${ }^{\wedge}$ The FRS provides logit scores ranging from 4.12 (very mild) to -4.99 (very severe). $n=$ number of patients normally reporting alcohol and regular smokers. All alcohol consumption was within normal guidelines (see text). 
Table 2. Measures of heart rate variability and autonomic function

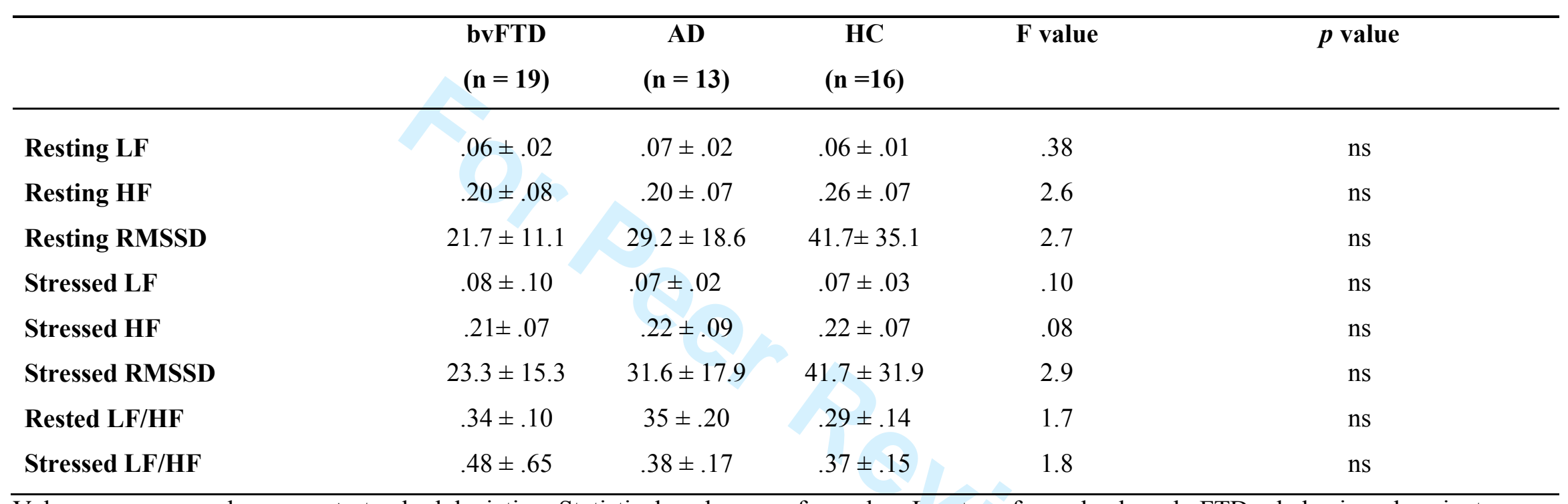

Values are expressed as mean \pm standard deviation. Statistical analyses performed on Log transformed values. bvFTD = behavioural-variant frontotemporal dementia; $\mathrm{AD}=$ Alzheimer's disease; $\mathrm{HC}=$ healthy controls; $\mathrm{LF}=$ low frequency; $\mathrm{HF}=$ high frequency; $\mathrm{RMSSD}=$ the square root of the mean squared difference of successive beat to beat intervals and a measure of vagal control of the heart 
Table 3. Average energy expenditure (kcal) per day in bvFTD, AD and healthy controls

\begin{tabular}{|c|c|c|c|c|c|c|}
\hline & bvFTD $^{a}$ & $\mathbf{A D}^{\mathbf{a}}$ & $\mathrm{HC}^{\mathrm{a}}$ & F value & $p$ value & Post hoc \\
\hline Resting energy & $1656.9 \pm 245.0$ & $1356.4 \pm 170.5$ & $1442.1 \pm 173.7$ & 6.4 & .005 & bvFTD $>$ HC $(p=.045)$ \\
\hline expenditure & & & & & & bvFTD $>\operatorname{AD}(p=.005)$ \\
\hline \multicolumn{7}{|l|}{ expenditure } \\
\hline Diet induced & $259.2 \pm 53.6$ & $202.9 \pm 43.9$ & $218.3 \pm 24.6$ & 5.0 & .013 & bvFTD $>$ HC $(p=.035)$ \\
\hline Total energy & $2592.4 \pm 533.9$ & $2028.5 \pm 440.9$ & $2182 \pm 246.4$ & 5.0 & .013 & $\operatorname{bvFTD}>\mathrm{HC}(p=.035)$ \\
\hline expenditure & & & & & & $\mathrm{bvFTD}>\mathrm{AD}(p=.013)$ \\
\hline Physical activity level & $1.6 \pm .3$ & $1.5 \pm .1$ & $1.5 \pm .1$ & .6 & .531 & - \\
\hline
\end{tabular}

Values are expressed as mean \pm standard deviation. bvFTD $=$ behavioural-variant frontotemporal dementia; $\mathrm{AD}=\mathrm{Alzheimer}$ 's disease; $\mathrm{HC}=$ healthy controls. ${ }^{a}$ Missing data: Data missing for 7 bvFTD, 3 AD and 5 HC. 
Table 4. Correlations between subcortical volumes and resting heart rate in bvFTD and AD

\begin{tabular}{lccccccc}
\hline & Thalamus & Caudate & Putamen & Pallidum & Hippocampus & Amygdala & Accumbens \\
\hline bvFTD & $-.349^{*}$ & -.334 & $-.342^{*}$ & -.197 & $-.529^{* *}$ & $-.352^{*}$ & $-.446^{*}$ \\
AD & .031 & .173 & .159 & .257 & .056 & -.004 & .026 \\
\hline
\end{tabular}

Values as expressed in Pearson's correlation coefficient scores. * Denotes that the correlation is significant at the 0.05 level. ** Denotes that the correlation is significant at the 0.01 level. Significant correlations after correction for multiple comparisons are highlighted in bold. bvFTD $=$ behavioural-variant frontotemporal dementia; $\mathrm{AD}=$ Alzheimer's disease. Statistical significance was set at $\mathrm{p}<.007$ Bonferroni corrected for multiple comparisons. 


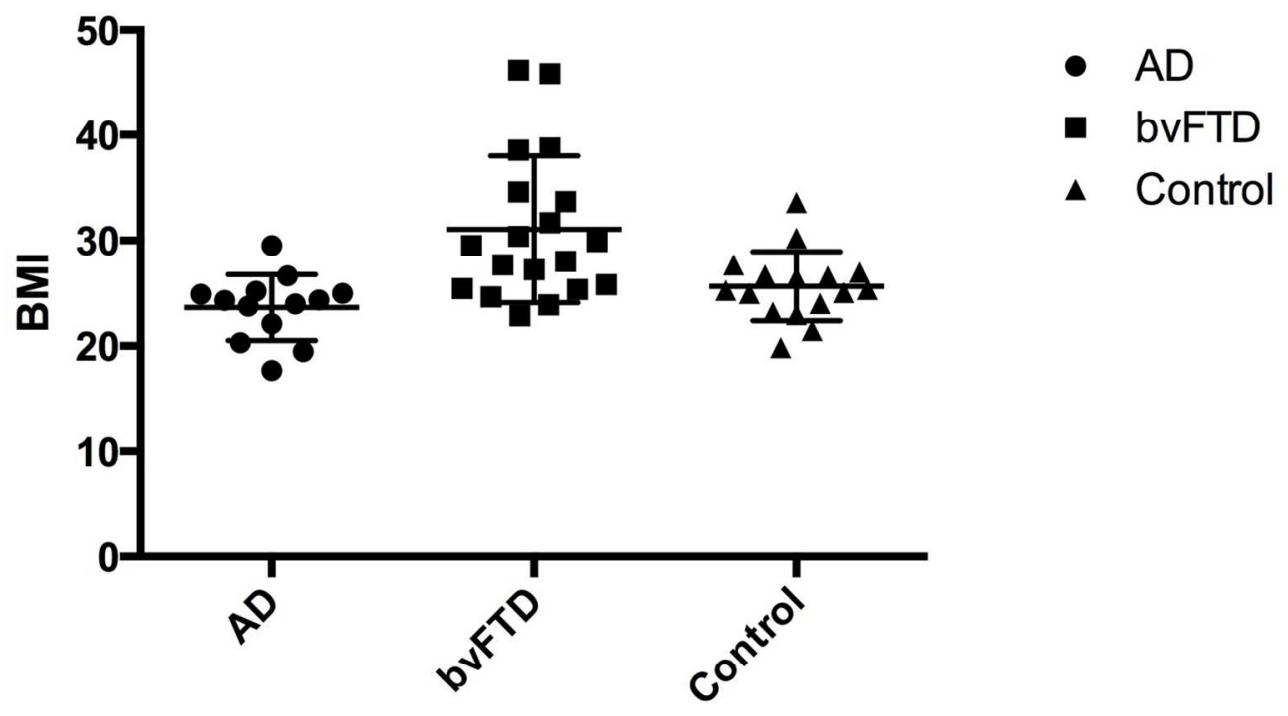

Diagnosis

Figure 1: Scatter plot showing BMI values in bvFTD, $A D$ and healthy controls Horizontal line represents mean $+/-$ SD. bvFTD $>$ AD and controls $(p<.001)$

$125 \times 78 \mathrm{~mm}(300 \times 300$ DPI $)$ 


\section{Resting and Stressed heart rate}

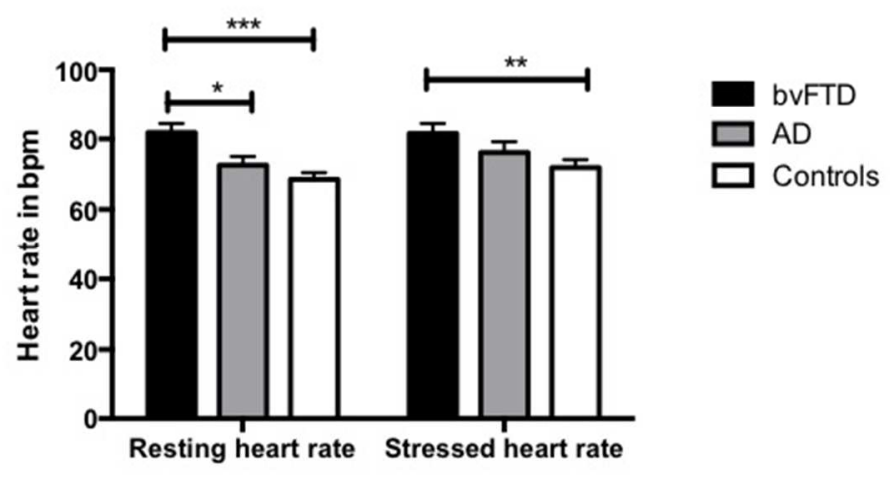

Figure 2. Resting and stressed heart rate in bvFTD, $A D$ and healthy controls

$*$ bvFTD $>$ AD $(p=.028), * *$ bvFTD $>$ Controls $(p=.037), * * *$ bvFTD $>$ Controls $(p=.001)$

$254 \times 190 \mathrm{~mm}(72 \times 72 \mathrm{DPI})$ 

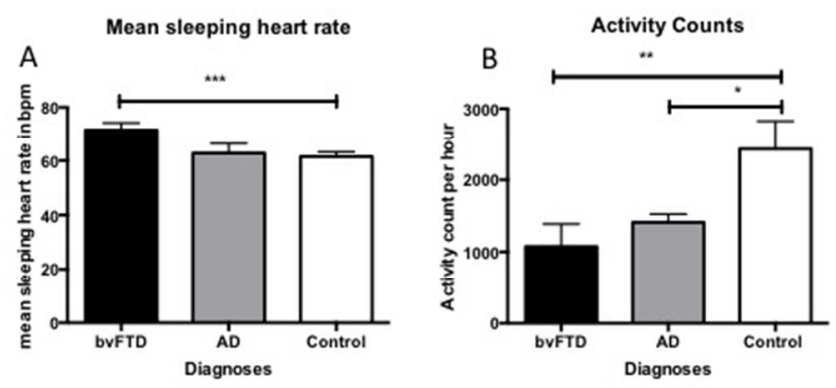

Figure 3. Long term Actiheart results

Mean sleeping heart rate. $* * *$ bvFTD $>$ controls $(p=.038)$; B) Mean activity counts per 24 hours. $*$ AD< Controls $(p=.05), * *$ bvFTD $<$ Controls $(p=.002)$

$254 \times 190 \mathrm{~mm}(72 \times 72 \mathrm{DPI})$ 


\section{right inferior parietal}
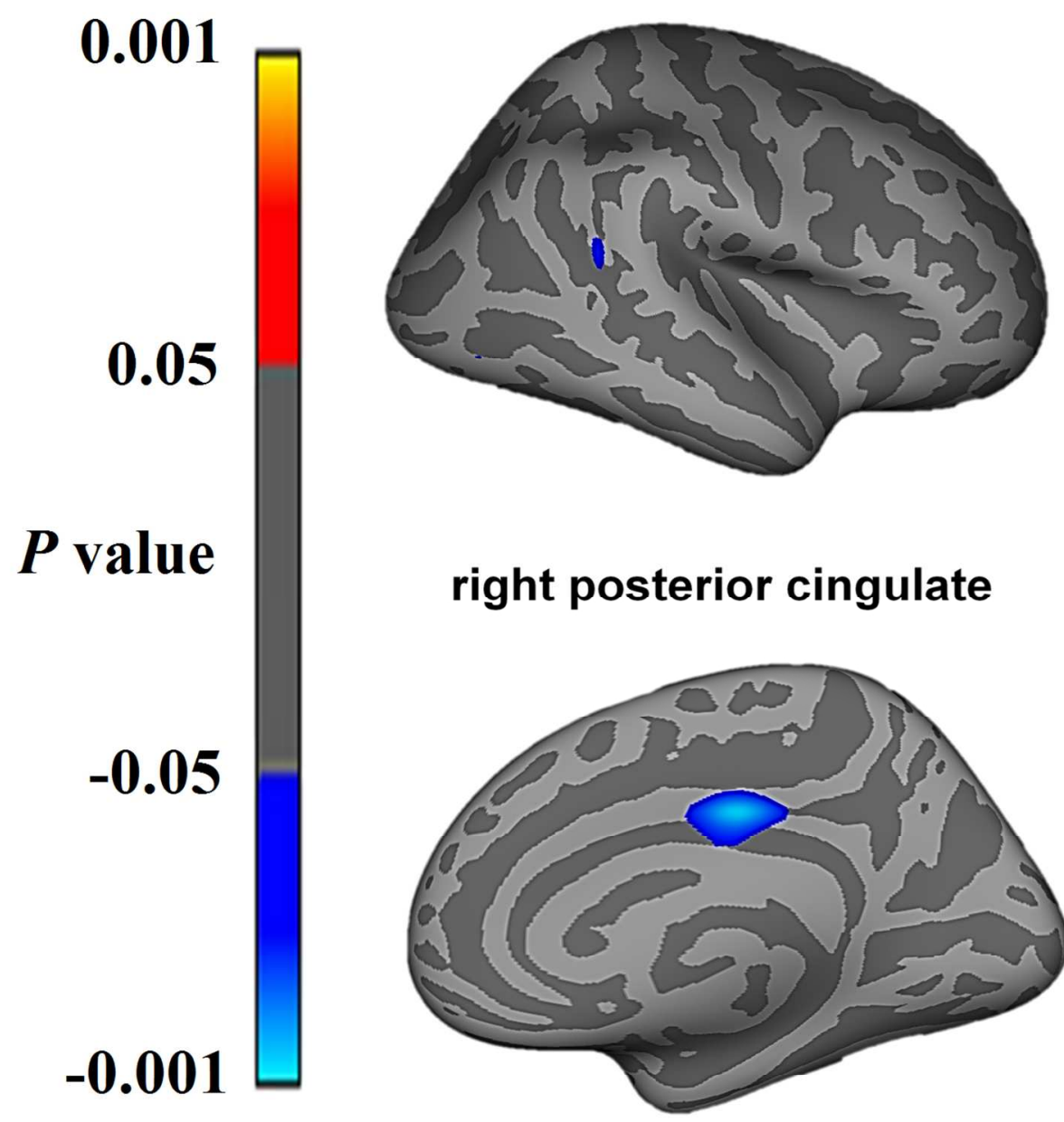

\section{right posterior cingulate}

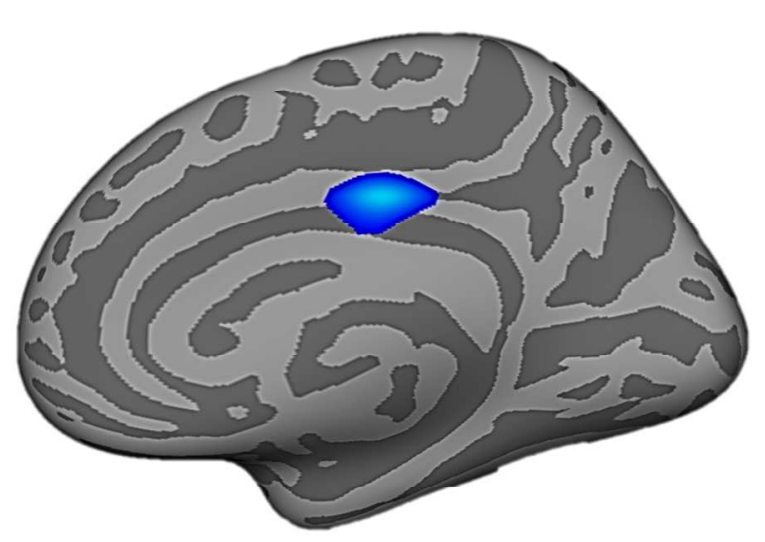

Figure 4. Regions showing significant correlations between cortical thinning and increasing resting heart rate in bvFTD and AD in whole brain imaging analyses. Statistical significance was set at $p<.001$ uncorrected for multiple comparisons. bvFTD = behavioural-variant frontotemporal dementia; $A D=$ Alzheimer's disease.

$$
369 \times 410 \mathrm{~mm} \text { (96 x } 96 \text { DPI) }
$$



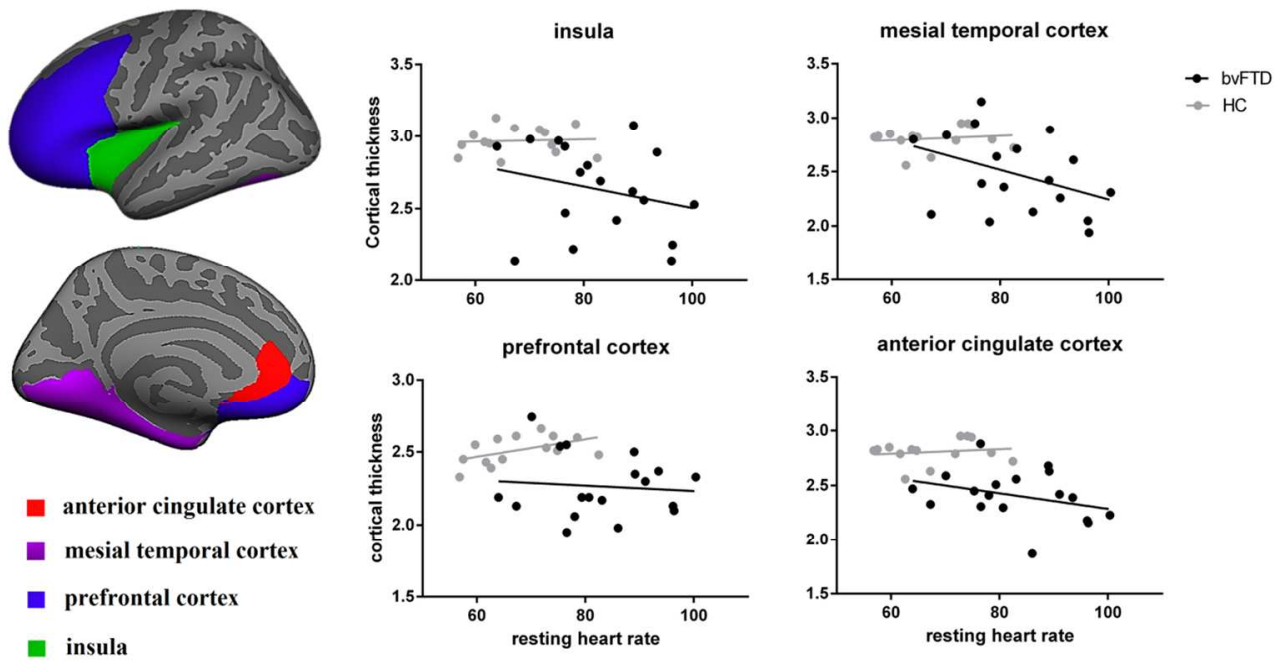

Figure 5. Significant associations between cortical thickness in preselected ROIs and resting heart rate in bvFTD and HC. No significant associations were seen in AD and HC. Statistical significance was set at $p<$ .0125 Bonferroni corrected for multiple comparisons. bvFTD = behavioural-variant frontotemporal dementia; $\mathrm{HC}=$ Healthy controls 
Supplementary table S1. Component sub-regions for cortical regions of interest analyses

\begin{tabular}{ll}
\hline Prefrontal cortex & Caudal middle frontal, rostral middle frontal, medial orbitofrontal, lateral orbitofrontal, pars opercularis, \\
& pars orbitalis and pars triangularis \\
Mesial temporal cortex & Fusiform, entorhinal, parahippocampal and lingual temporal regions \\
Anterior cingulate cortex & Caudal anterior cingulate and rostral anterior cingulate \\
Insula & Anterior (inferior and superior) and posterior insular regions \\
\hline
\end{tabular}

Component sub-regions were identical in both hemispheres. 
Supplementary Table S2. Measurements of subcortical brain regions in bvFTD, AD and healthy controls

\begin{tabular}{|c|c|c|c|c|c|}
\hline Brain measure & $\begin{array}{l}\text { bvFTD } \\
(n=18)\end{array}$ & $\begin{array}{c}\text { AD } \\
(n=13)\end{array}$ & $\begin{array}{c}\text { HC } \\
(n=14)\end{array}$ & $p$ value & Post hoc \\
\hline Thalamus & $4.5 \pm 0.8$ & $4.5 \pm 0.6$ & $5.0 \pm 0.6$ & $\mathrm{~ns}$ & - \\
\hline Caudate & $1.8 \pm 0.7$ & $2.2 \pm 0.2$ & $2.4 \pm 0.4$ & 0.01 & $\begin{array}{c}\text { bvFTD, } \mathrm{AD}< \\
\mathrm{HC}\end{array}$ \\
\hline Putamen & $2.8 \pm 0.6$ & $3.0 \pm 0.4$ & $3.6 \pm 0.5$ & 0.001 & $\begin{array}{c}\text { bvFTD, } \mathrm{AD}< \\
\mathrm{HC}\end{array}$ \\
\hline $\begin{array}{l}\text { Globus } \\
\text { Pallidus }\end{array}$ & $0.9 \pm 0.2$ & $1.0 \pm 0.1$ & $1.0 \pm 0.2$ & ns & - \\
\hline Hippocampus & $2.4 \pm 0.6$ & $2.2 \pm 0.6$ & $3.1 \pm 0.3$ & $<0.001$ & $\begin{array}{c}\text { bvFTD, } \mathrm{AD}< \\
\mathrm{HC}\end{array}$ \\
\hline Amygdala & $1.0 \pm 0.3$ & $0.9 \pm 0.2$ & $1.3 \pm 0.2$ & 0.001 & $\begin{array}{c}\text { bvFTD, } \mathrm{AD}< \\
\mathrm{HC}\end{array}$ \\
\hline $\begin{array}{l}\text { Nucleus } \\
\text { Accumbens }\end{array}$ & $0.2 \pm 0.1$ & $0.3 \pm 0.1$ & $0.4 \pm 0.1$ & $<0.001$ & $\begin{array}{c}\text { bvFTD, } \mathrm{AD}< \\
\mathrm{HC}\end{array}$ \\
\hline
\end{tabular}




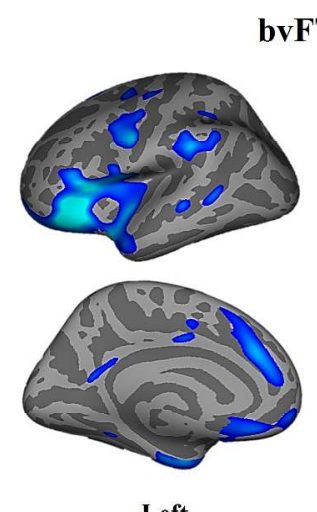

bVFTD

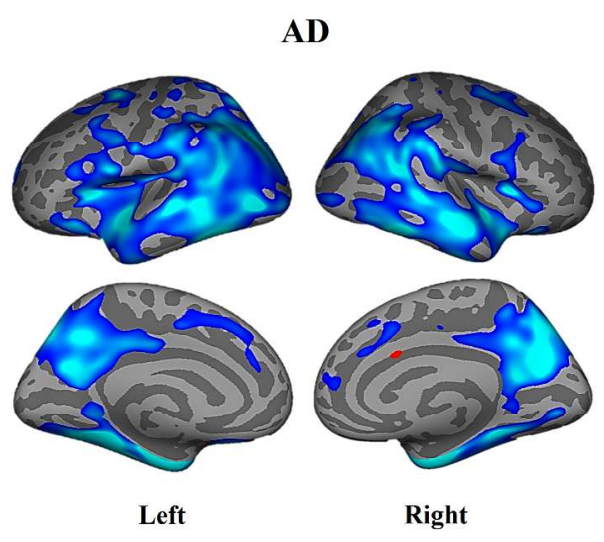

$\begin{array}{cccc}0.001 & 0.05 & P \text { value }-0.05 & -0.001 \\ \text { Patients }>\text { HC } & \text { FDR corrected } & \text { Patients }<\text { HC }\end{array}$ 


\title{
Energy expenditure in frontotemporal dementia: a behavioural and imaging study
}

\author{
Rebekah M Ahmed MBBS, FRACP ${ }^{1,2,3,5}$, Ramon Landin--Romero $\mathrm{PhD}^{1,2,3}$, Tinh--Hai \\ Collet $\mathrm{MD}^{4}$, Agatha A. van der Klaauw $\mathrm{MD} \mathrm{PhD}^{4}$, Emma Devenney ${ }^{1,2,3,5}$, Elana \\ Henning $\mathrm{BSc}^{4}$, Matthew C. Kiernan $\mathrm{DSc}^{5}$, Olivier Piguet $\mathrm{PhD}^{1,2,3}$, I. Sadaf Farooqi \\ MB.ChB, $\mathrm{PhD}^{4}$, John R Hodges MD, FRCP ${ }^{1,2,3}$.
}

${ }^{1}$ Neuroscience Research Australia, Sydney, Australia

${ }^{2}$ University of New South Wales, Sydney, Australia

${ }^{3}$ ARC Centre of Excellence in Cognition and its Disorders, the University of New South Wales, Sydney, 2031 Australia

${ }^{4}$ University of Cambridge Metabolic Research Laboratories and NIHR Cambridge Biomedical Research Centre, Wellcome Trust-MRC Institute of Metabolic Science, Addenbrooke's Hospital, Cambridge, United Kingdom

${ }^{5}$ Brain \& Mind Centre, Sydney Medical School, University of Sydney, 2000, Australia

\section{Corresponding Author}

Dr Rebekah Ahmed and Professor John Hodges

Neuroscience Research Australia,

Barker St, Randwick

NSW 2031, Australia

Phone: +61 293991000 Fax: +61 293991646

E-mail: rebekahahmed@gmail.com and j.hodges@neura.edu.au

\section{Abstract word count: 3215 \\ Word count: $4984 \underline{5935744}$}

References: 72

Figures: $\underline{5} 4$

Tables: 4

\section{Supplementary files: 3}

Key words: Frontotemporal dementia, metabolism, heart rate, physiology, autonomic function. 


\begin{abstract}
Abnormal eating behaviour and metabolic parameters including insulin resistance, dyslipidaemia and body mass index are increasingly recognized as important components of neurodegenerative disease and may contribute to survival. It has previously been established that behavioural variant frontotemporal dementia is associated with abnormal eating behaviour characterised by increased sweet preference. In this study, it was hypothesized that behavioural variant frontotemporal dementia might also be associated with altered energy expenditure. A cohort of 19 patients with behavioural variant frontotemporal dementiabvFTD, 13 with Alzheimer's disease and 16 (age- and sex- matched) healthy controls were studied using Actiheart devices (CamNtech, UK) to assess resting and stressed heart rate. Actiheart devices were fitted for 7 days to measure sleeping heart rate, activity levels, and resting, active and total energy expenditure. Using high resolution structural MRI the neural correlates of increased resting heart rate were investigated including cortical thickness and region of interest analyses. In behavioural variant frontotemporal dementia, resting $(p=.001)$, stressed $(p=.037)$ and sleeping heart rate $(p=.038)$ were increased compared to controls, and resting heart rate $(p=.020)$ compared to Alzheimer Disease patients. Behavioural variant frontotemporal dementia was associated with decreased activity levels compared to controls $(p=.002)$ and increased resting energy expenditure $(p=.045)$ and total energy expenditure $(p=.035)$. Increased resting heart rate correlated with behavioural (Cambridge Formatted: Font: Italic Behavioural Inventory) and cognitive measures (Addenbrooke's Cognitive Examination). Increased resting heart rate in behavioural variant frontotemporal dementia correlated with atrophy involving the mesial temporal cortex, insula, and amygdala, regions previously suggested to be involved exclusively in social and
\end{abstract}


emotion processing in frontotemporal dementia. These neural correlates overlap the network involved in eating behaviour in frontotemporal dementia suggesting, a complex interaction between eating behaviour, autonomic function and energy homeostasis. As such the present study suggests that increased heart rate and autonomic changes are prevalent in behavioural variant frontotemporal dementiabvFTD, and are associated with changes in energy expenditure. An understanding of these changes and neural correlates may have potential relevance to disease progression and prognosis. 


\section{Introduction}

Traditionally Frontotemporal dementia (FTD) has been viewed as a syndrome characterised by behavioural and cognitive changes, although increasingly it is beingeen recognised that there is involvement of networks that affect physiological processing including somatosensory processing including pain and temperature (Fletcher et al., 2015a; Fletcher et al., 2015b), autonomic processing (Ahmed et al., 2015a; Guo et al., 2016), and neuroendocrine and metabolic changes (Ahmed et al., 2014b; Ahmed et al., 2015b). In behavioural variant frontotemporal dementia (bvFTD), eating behavioural changes are common, including hyperphagia, increased sweet preference and changes in food preference that may be associated with increased body mass index (BMI), dyslipidaemia and insulin resistance (Ahmed et al., 2014b). It has been suggested that given the prevalence of these eating behaviourat ehanges, alterations in BMI are less than expected for the increased energy intake, suggesting changes in energy expenditure (Woolley et al., 2007; Ahmed et al., 2016a).

In several neurodegenerative diseases it is established that there are changes in metabolic parameters. One such condition is ALS, which shares a clinical and pathological overlap with FTD and where consistent changes have been found (Ahmed et al., 2016b), including increased resting energy expenditure in up to $50 \%$ of patients (Bouteloup et al., 2009; Vaisman et al., 2009). It has also been suggested that the hypermetabolic state (defined as increased energy expenditure) is intrinsically linked to the process of neurodegeneration with several animal models of TDP-43 and the C9ORF72 gene expansion exhibiting hypermetabolism and weight loss (Dupuis et al., 2004)(Chiang et al., 2010; Shan et al., 2010; Xu et al., 2010; Koppers et al., 2015).

Given the significant overlap between FTD and ALS at a clinical, pathological and genetic level, it seems plausible that changes in energy expenditure may also be present in FTD (Ahmed et al., 2016b). In addition, the changes in appetite appear to exceed the minor increments in BMI and weight gain seen in bvFTD, suggesting increased energy expenditure may also contribute to the body weight changes seen in patients (Woolley et al., 2007; Ahmed et al., 2014a). This is also suggested by the 
fact that in studies measuring caloric intake in FTD, adapted from obesity research,

BMI does not correlate with caloric intake, suggesting other factors are at play

(Ahmed et al., 2016a)_Energy expenditure, which includes basal metabolic rate (amount of energy expended at rest) and active energy expenditure (a combination of activity levels and heart rate), has not been investigated in bvFTD. Intrinsically linked with energy expenditure are potentially alterations in autonomic activity including

heart rate, heart rate variability, and sympathetic and parasympathetic drive_(Messina et al., 2013). Changes in the autonomic nervous system, particularly in the sympathetic nervous system have also been proposed to affect glucose and fat

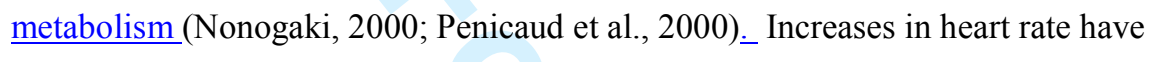
been found to predict an increase in metabolic rate and energy expenditure, via an increase in circulatory rate and oxygen consumptions (Berggren and Hohwu Christensen, 1950).

Measurement of energy expenditure in free-living individuals is challenging. In this study, we used digital heart rate/activity monitoring (Brage et al., 2004; Brage et al., 2005; Crouter et al., 2008) to examine changes in heart rate (rest, stressed and sleep), activity levels and energy expenditure and the potential correlations that this has to autonomic function in a large group of bvFTD patients, compared to a disease comparison group (Alzheimer's disease, AD) and healthy controls. This approach has been used previously in genetic obesity research but not in patients with neurodegeneration (Pearce et al., 2013). The potential neurobiological underpinnings of increases in heart rate were further examined using structural MRI imaging to provide insight into the neural correlates controlling energy expenditure and autonomic function in FTD. 


\section{Methods}

\section{Participants}

Formatted: Font: Italic

Thirty-two patients with dementia (19 bvFTD, 13 AD) were recruited from Forefront, Neuroscience Research Australia. These individuals were compared with 16 age- and sex-matched healthy controls. All patients underwent neurological review, cognitive assessment and met current clinical diagnostic criteria for probable bvFTD or AD (McKhann et al., 2001; Gorno-Tempini et al., 2011; McKhann et al., 2011; Rascovsky et al., 2011). Disease severity was established using the Frontal Rating Scale (FRS) (Mioshi et al., 2010). Controls were recruited from the Neuroscience Research Australia Volunteer database. Healthy controls scored above 88/100 on the Addenbrooke's Cognitive Examination-III (Hsieh et al., 2013) and 0 on the sum of boxes score of the Clinical Dementia Rating scale (Morris, 1993). Exclusion criteria for patients and controls included concurrent psychiatric disturbance, other neurodegenerative conditions or neurological disorders and/or history of substance abuse.

\section{Patient medical history and medications}

Patients medical records and list of medications were obtained from their general practitioner. Given that the study measured heart rate variations, patients with a known cardiac rhythmic disorder e.g. atrial fibrillation, supraventricular tachycardia or conduction delays were excluded from the study ( 2 patients in total 1 bvFTD and 1 AD patient). Patient's, their carers and controls were asked about their current $\underline{\text { smoking status and alcohol intake. }}$

\section{Ethics}

Formatted: Font: Bold, Italic

This study was approved by the South Eastern Sydney Local Health District and the University of New South Wales human ethics committees. Written informed consent was obtained from each participant and/or their primary caregiver.

-

Physiological measurements: Actiheart device

Formatted: Font: Italic

Formatted: Font: Bold, Italic

Formatted: Font: Italic 
Participitants were fitted with the Actiheart device (CamNtech, Cambridge, UK) a compact device designed to quantify heart rate, activity and energy expenditure (Brage et al., 2004; Brage et al., 2005; Crouter et al., 2008). The Actiheart has two clips which are attached directly to standard ECG electrodes. One electrode was attached to V1 on the chest ( ${ }^{\text {th }}$ right intercostal space) and the second electrode was placed $10 \mathrm{~cm}$ away on the left mid-clavicular line. The number of $\mathrm{R}$ waves detected is recorded at 15 -second epochs and from this the heart rate is derived.

Simultaneously, A an internal triaxial accelerometer senses the frequency and intensity of the participant's torso movements -including walking and pacing from which and activity counts are derived. When placed in short term mode, the Actiheart measures heart rate variability, heart rate and inter-beat interval (IBI) of the heart rate, with an epoch length of 15 seconds. Long term recordings in long term mode provide mean heart rate and activity levels over an epoch of 15 seconds and recordings can be made for up to 11 days (Brage et al., 2004; Brage et al., 2005; Crouter et al., 2008).

\section{Measurement of heart rate}

To measure resting and stressed heart rate participants wore the Actiheart in short term recording mode for a period of 6 hours following a standard protocol, described briefly. After arriving fasted (10 hours) and an initial period of introduction patients were given a set breakfast that measured caloric intake (Ahmed et al., 2016a), no caffeine or tea was included in this breakfast to avoid their chronotropic effects-on heart rate.; Pparticipants were then asked to rest in a lounge environment and their resting heart rate was obtained over a period of 30 minutes. Following this, participants were then taken into a room and took part in 2 hours of cognitive testing. The initial 30 minutes of this period was taken as the stressed heart rate. Resting and stressed heart rates and measures of autonomic function were obtained after entering the beat-to-beat RR interval data obtained by the Actiheart into Kubios HRV, an advanced and easy to use software for heart rate variability (HRV) analysis (Tarvainen et al., 2014). The following measures were obtained: the root mean squared of successive differences (RMSSD), which is a measure of vagal control of the heart (DeGiorgio et al., 2010); the low frequency (LF), which corresponds to the $0.10 \mathrm{~Hz}$ slow fluctuations of arterial pressure and reflects sympathetic and parasympathetic tone; the high frequency (HF) which corresponds to $\sim 0.25 \mathrm{~Hz}$ fluctuations and is a measure of respiratory sinus arrhythmias and can be considered 
an index of vagal modulation; and the LF/HF ratio which is used to indicate balance between sympathetic and parasympathetic tone.

\section{Long term activity}

Following the short term analyses, participants were fitted with the Actiheart in long term mode and asked to wear this at home for 7 days to provide continuous heart rate and activity monitoring. The participants wore the device continuously and were allowed to shower with the device. Carers were given instructions to refit the device if it became loose or was removed. From the long-term recording, sleeping heart rate and activity counts were calculated.

\section{Measurement of sleeping heart rate}

Sleeping heart rate was calculated over a period of 1 night. For each participant, the 1 night was selected from the 7 day long term recording where a period of recording of uninterrupted sleep was obtained, between midnight and 5 am where no activity was detected. From this period, the average sleeping heart rate, minimum and maximum heart rate was calculated for each participant. Investigators were blinded to the patient ID and diagnoses for this selection. Sleeping heart rate was calculated over a period of 1 night. For each participant, the 1 night was selected from the 7 day long term recording where a period of recording of uninterrupted sleep was obtained, with the most reliable recording. The patient ID and diagnoses was blinded for this selection. This was defined as a period between midnight and $5 \mathrm{am}$ where no activity was detected. From this period, the average sleeping heart rate, minimum and maximum heart rate was calculated for each participant.

\section{Measurement of activity over 24 hours}

An average activity count over 24 hours was calculated for each participant. This was obtained by selecting a 24-hour period in the 7 day long-term recording where continuous recording was available for each patient. This was found to be day 2 in each patient as the Actiheart had been firmly attached and had not been removed, which tended to occur as the long term recording proceeded. The average activity counts for each patient over these 24 hours was obtained and expressed as an activity count per 24 hours. Significance levels between group means were examined after correcting for age and sex. 


\section{Measurement of energy expenditure}

The Actiheart measures heart rate and activity simultaneously and these data are transferred to the Actiheart software which uses a validated branched model equation (Brage et al., 2004; Brage et al., 2005) to derive active energy expenditure for each epoch using a combination of heart rate and activity. Using the branched model equation, group Cal JAP2007 (CamNtech, Cambridge, UK) measures of daily energy expenditure were calculated for each participant each day for 7 days and an average over this period obtained. The following measures were obtained: Activity Energy expenditure (AEE) derived from the branched model equation, which includes a combination of heart rate and activity measures; Resting energy expenditure (REE) derived from the Schofield equation, designed to measure basal metabolic rate adjusted for weight (Schofield, 1985); Dietary induced thermogenesis (DIT), estimated as $10 \%$ of total energy expenditure; Total energy expenditure $(\mathrm{TEE})=$ REE + AEE + DIT; Physical activity level $(\mathrm{PAL})=$ TEE/REE.

\section{Behavioural measurements}

Formatted: Font: Italic In addition to measurements of heart rate variability, activity and energy expenditure, changes in eating behaviour were measured using caregiver-based questionnaires: the Appetite and Eating Habits Questionnaire (APEHQ) (Ikeda et al., 2002; Ahmed et al., 2014a) and the Cambridge Behavioural Inventory (CBI) (Bozeat et al., 2000). These surveys were completed on the same day the short term recordings were obtained and were felt to be representative of intake over the proceeding 7 days when the long term recordings were obtained. The APEHQ provides measures of nicotine and alcohol consumption. Height and weight were measured barefoot and body mass index (BMI) calculated (weight in kilograms/height in metres squared).

$$
\Delta-
$$

s barefootcalculatedweight in kilograms height in metres squaredIn addition to measurements of heart rate variability, activity and energy expenditure, changes in eating behaviour were measured using caregiver based questionnaires: the Appetite and Eating Habits Questionnaire (APEHQ) (Hkeda et al., 2002; Ahmed et al., 2014a) and the Cambridge Behavioural Inventory (CBI) (Bozeat et al., 2000). Height and weight were measured (shoes removed) to derive the body mass index (BMI, unit: $\mathrm{kg} /$ meter $\left.^{2}\right)$. 
Imaging

MRI acquisition and preprocessing
Formatted: Font: Not Italic

Formatted: Font: Italic

All participants underwent whole brain structural MRI with a 3 T Phillips scanner using a standard 8-channel head coil. 3D high-resolution turbo field echo T1weighted sequences were acquired with the following parameters: coronal orientation, matrix $256 \times 256,200$ slices, $1 \mathrm{~mm} 2$ in-plane resolution, slice thickness $1 \mathrm{~mm}$, echo time/repetition time $2.6 / 5.8 \mathrm{~ms}$, flip angle $\alpha=8^{\circ}$. MRI scans were obtained on the same day as the physiological and behavioural assessment.

Before analyses, the two T1 volumes were merged and averaged to increase the signal to noise ratio and the grey matter-white matter contrasts in brain structures.

FreeSurfer software, version 5.3.0 (http://surfer.nmr.mgh.harvard.edu) was used for surface-based cortical processing (Dale et al., 1999; Fischl et al., 1999) using standard methods (Fischl and Dale, 2000). Cortical thickness was smoothed with a $20 \mathrm{~mm}$ fullwidth at half-height Gaussian kernel. This level of blurring kernel was chosen to reduce the impact of imperfect alignment between cortices and thereby improve the signal-to-noise ratio (Lerch and Evans, 2005).

In addition, the following subcortical structures were automatically segmented and extracted for both hemispheres: thalamus, caudate, putamen, globus pallidus, hippocampus, amygdala, and nucleus accumbens. For these subcortical structures, measurements from both hemispheres were averaged and adjusted for total intracranial volume, in line with previous methodology (Voevodskaya et al., 2014).

All the resulting images were visually inspected and manually corrected in the event of tissue segmentation errors. One bvFTD patient and 2 healthy controls were excluded due to excessive surface or subcortical segmentation errors. Thus, 18 bvFTD, $13 \mathrm{AD}$ and 14 healthy controls were included in the imaging analyses.

\section{Statistical analyses}

Demographic and physiological variables 
Analyses were conducted using IBM SPSS statistics (version 21.0). KolmogorovSmirnov tests were run to determine suitability of variables for parametric analyses. One-way analyses of variance (ANOVA), followed by Tukey post hoc tests, were used to determine group differences in demographic and clinical variables (age, ACER). Categorical variables were analyzed using chi-square analyses. Independent t-tests were used to determine differences between bvFTD and AD for disease duration, abnormal behaviour (total CBI, CBI behavioural) and eating behaviour (APEHQ, CBI eating, and BMI) ( $p \leq 0.05$ regarded as significant). Measurements of heart rate (resting and stressed), autonomic function (resting and stressed LF, HF, RMSSD after log transformation), activity counts and energy measures (REE, AEE, DIT, PAL) were also explored using ANOVA, followed by Tukey post hoc tests. The relationship between resting heart rate and disease duration, BMI, eating behaviour (APEHQ total score) cognitive status (ACE-III) and behavioural measures (CBI total, eating and behavioural) were further explored using Pearson rank correlations corrected for multiple comparisons ( $p \leq 0.01$ regarded as significant).

\section{Imaging data analyses}

For cortical thickness, sets of vertex-by-vertex analyses were performed using general linear models aimed to examine differences in cortical thickness between groups and then to estimate the neural correlates for the physiological variables where bvFTD showed significant differences with both $\mathrm{AD}$ and healthy controls (resting heart rate and stressed heart rare). In the first set of analyses, overall cortical thickness of both hemispheres was modelled including cortical thickness as a dependent variable and group (bvFTD, AD, healthy controls) as an independent variable. In the second set of analyses, we created separate linear models, one for each physiological variable under examination. Each model included the following repressors: group (bvFTD, AD, healthy controls), the physiological variable (resting heart rate, stressed heart rare) and the interaction between group and the physiological variable. To determine physiological associations with cortical thickness specific to diagnostic group, we focused on the interaction effect between each diagnosis and each physiological variable. Correlations between physiological variables and cortical thickness were investigated first by combining all participants (behavioural variant FTD, ,

Alzheimer's disease, controls) and then in each patient group combined with controls, to identify neural correlates of resting and stressed heart rate to each patient group.. 
Since the groups were matched at baseline for age, sex and duration of disease, no covariates were included in the models. Statistical significance was set at $p=0.001$ uncorrected for multiple comparisons. In addition, we used a conservative cluster extent threshold of $\mathrm{k}>50 \mathrm{~mm}^{2}$. This approach is designed to minimize Type I error while balancing the risk of Type II error (Lieberman and Cunningham, 2009).

For the subcortical regions, group comparisons of subcortical volumes between bvFTD, AD and healthy controls were performed using ANOVA. Post hoc analyses were corrected for multiple comparisons using a Sidak adjustment. Next, in order to uncover the subcortical grey matter correlates of resting heart rate and stressed heart rate, correlations were investigated using the same approach outlined above. Pearson two-tailed correlational analyses were conducted with Bonferroni correction for multiple comparisons $(p<\propto / k=.007)$.

\section{Region of interest analyses}

In addition to the whole-brain analyses, a set of cortical regions of interest (ROI) were selected and computed and averaged from the regional parcellations provided by FreeSurfer for both hemispheres. These regions were selected according to previous findings in the literature examining associations between autonomic function (e.g., pain and temperature and heart rate) and brain regions in bvFTD and AD and normal controls (Critchley et al., 2003; Jones, 2011; Fletcher et al., 2015a). The regions selected included the prefrontal, mesial temporal and anterior cingulate cortices, and the insula. Details on the computation of these measurements can be found in Supplementary Table S1. Pearson two-tailed correlations were used to examine associations between these ROIs and the resting and stressed heart rate. These analyses were Bonferroni corrected to control for multiple comparisons $(p<\propto / k=$ $.0125)$. 


\section{Results}

Participants groups were representative of the diseases studied and did not differ in sex distribution, age or disease duration (Table 1 , all $p$ values $>0.365$ ). Group differences were observed on measures of cognition (ACE-III), behavioural measures and eating behaviour (Table 1) and were in keeping with the known behaviour of the diagnostic groups. On the ACE-III as expected the patient groups scored lower than controls $(p<.001)$. The bvFTD group was more functionally impaired relative to AD (FRS; $\mathrm{t}=3.3, p=.03$ ). The bvFTD group as expected scored higher than the AD group on the total CBI score $(\mathrm{t}=3.6, p=.001)$, and CBI behavioural score $(\mathrm{t}=4.1, p$ $<.001)$.

\section{Medications, smoking and alcohol intake (Table 1)}

As expected, a higher number of AD patients were on cholinesterase inhibitors $(9$ patients) compared to the bvFTD ( 2 patients) and control (no patient) groups. There was no difference in the number of patients treated with a medication likely to affect heart rate and cardiac conduction (e.g. beta blocker, calcium channel blocker) between the groups. One bvFTD patient was on stable and adequate thyroxine treatment. Two bvFTD patients and 2 control subjects were current smokers. Eight bvFTD patients carers reported that they consumed alcohol normally, less than weekly in 4 and several times per week in 4 . Ten control subjects reported alcohol consumption, 4 less than weekly and 6 several times a week. Five AD patients reported alcohol intake regularly, 2 several times a week and 3 less than weekly. No patient or control participant stated that they consumed more alcohol than the recommended amount by the Australian National Health and Medical research $\underline{\text { council. }}$

\section{Eating behaviour and BMI}

On both the APEHQ and CBI eating score and CBI eating total $(t=4.1, p<.001)$. tThe bvFTD group showed more severe eating disturbance based on caregiver surveys compared with AD $(\mathrm{t}=4.1, p<.001)$. The bvFTD group had an increased BMI (Figure 1) compared to the $\mathrm{AD}(p=.001)$ and Control groups $(p=.008)$ (Table 1$)$.
Formatted: Font: Bold

Formatted: Font: Not Italic
Formatted: Font: Bold

Formatted: Font: Bold 


\section{[INSERT FIGURE 1 HERE]}

\section{Heart rate and autonomic function}

Significant group differences were present for both resting $(\mathrm{F}=8.6, p=.001)$ and stressed $(\mathrm{F}=3.2, p=.047)$ heart rate measures. The bvFTD group (mean $=81.8 \mathrm{bpm}$ had an increased resting heart rate compared to both the control (mean $=68.5 p=$ .001 ) and $\mathrm{AD}$ groups (mean $=72.5, p=.020$ ) and an increased stressed heart rate compared to the control group $(\mathrm{bvFTD}=81.5, \mathrm{AD}=76.1$, Control $=71.9 ; p=.037)$ (Figure-Figure 24). On measures of autonomic function (Table 2), no significant group differences were detected; however, a trend for the bvFTD group to have a decreased RMSSD value, in both resting $(p=.076)$ and stressed states $(p=.063)$ was present

\section{[INSERT FIGURE $\underline{2}+$ HERE]}

\section{Correlations of resting heart rate with behavioural measures}

When all groups were combined, resting heart rate was positively correlated with behavioural and eating changes as reflected by the CBI total ( $r=.417, p=.004)$, CBI behavioural $(r=.451, p=.001)$, and total CBI eating score $(r=.307, p=.01)$, and negatively correlated with cognitive function on the ACE-III $(r=-.314, p=.01)$, functional ability on the FRS ( $r=-.308, p=.05)$. As in prior studies, an increased BMI correlated with behavioural changes on the CBI total $(r=.369, p=.01)$, CBI behavioural $(r=.334, p=.01)$, and total CBI eating score $(r=.397, p=.006)$, and the APEHQ $(r=.461, p=.01)$. BMI did not correlate with resting heart rate $(r=$ $.206, p=.160)$.

\section{Long term Actiheart recordings}

Long-term recordings over 7 days were obtained for $1 \underline{2}+\mathrm{bvFTD}, 10 \mathrm{AD}$, and $\underline{119}$ control participants to measure sleeping heart rate and activity levels. Several bvFTD patients refused to wear the Actiheart or when at home disposed of it. The patients in the subset analyses did not differ from the larger group in which short term recordings and imaging correlation were conducted.

\section{Sleeping heart rate}


As with resting and stressed heart rate significant group differences were also detected in mean sleeping heart rate (Figure $\underline{3} z a)(F=3.9, p=.032)$ with the bvFTD group (mean $=71.6 \mathrm{bpm}$ ) having an increased sleeping heart rate compared to the control group (mean $=61.5 \mathrm{p}=.038)$ and a trend compared to the $\mathrm{AD}$ group (mean $=$ $62.8 \mathrm{p}=.085)$. No group differences $(\mathrm{F}=1.4 p=.270)$ in mean minimum heart rate were detected between the bvFTD $(58.9 \pm 7.3 \mathrm{bpm}), \mathrm{AD}(54.7 \pm 8.2)$ and control groups $(55.1 \pm 5.2)$. By contrast, the bvFTD group $(100.2 \pm 13.9)$ had an increased maximum heart rate compared to the control group $(95.7 \pm 14.3 \mathrm{bpm} ; \mathrm{F}=4.2 \mathrm{p}=$ $.025)$.

\section{Activity levels}

Group differences were detected on activity counts (Figure $\underline{3} z$ b) over a 24 hour period, after correcting for age and sex. Contrary to what was expected both the $\operatorname{bvFTD}(p=.002)$ and AD groups $(p=.05)$ showed significantly decreased activity counts per hour compared with the controls, suggesting particularly that the bvFTDis group has reduced activity levels.

\section{[INSERT FIGURE $\underline{3} z$ HERE]}

\section{Energy expenditure}

On examination of energy expenditure group differences were present (Table 3), with the bvFTD group having an increased resting energy expenditureREE compared to the control $(\mathrm{p}=.045)$ and $\mathrm{AD}(\mathrm{p}=.005)$ groups. The bvFTD group also had an increased diet induced thermogenesisDIT and total energy expenditureTEE compared to the other groups. Despite the finding of decreased activity counts in bvFTD, no significant group differences in active energy expenditureAEE were observed (calculated as a combination of heart rate and activity levels), suggesting that the decreased activity counts in bvFTD may not have affected the active energy expenditure, $\mathrm{AEE}$ due to the increased heart rate seen in this group.

\section{Imaging analyses}

\section{Atrophy analyses}


Group comparisons between each clinical group and controls revealed the characteristic profiles of brain atrophy previously reported as consistent with a diagnoses of bvFTD and AD. These results are presented in Supplementary Figure S1 and Supplementary Table S2. In brief, bvFTD patients showed atrophy in the insula and inferior frontal and anterior temporal cortices. In contrast, AD patients demonstrated widespread and bilateral atrophy involving parietal, temporal and to a lesser extent frontal regions, compared with controls. In addition, both clinical groups showed atrophy in all subcortical structures measured compared with controls, with the exception of the thalamus and the globus pallidus (Supplementary Table S2). The amount of atrophy in these structures was of similar magnitude in bvFTD and AD.

\section{Neural correlates of resting and stressed heart rate}

Unbiased whole brain analyses yielded a significant association between increasing resting heart rate and cortical thinning in the right posterior cingulate and right inferior parietal cortex when combining bvFTD and AD patients together (Figure 43).

\section{[INSERT FIGURE $\underline{4} 3$ HERE]}

In bvFTD but not in $\mathrm{AD}$, increased resting heart rate was associated with volume reductions in the thalamus $(r=-.349, p=.05)$, caudate $(r=-.334, p=.06)$, putamen $(r$ $=-.342, p=.05)$, hippocampus $(r=-.529, p=.002)$, amygdala $(r=-.353, p=.04)$ and nucleus accumbens $(r=-.446, p=.01)$, structures which are known in normal controls to be involved in autonomic regulation. Of these correlations, only the association between reduced hippocampal volume and increased resting heart rate survived conservative Bonferroni correction for multiple comparisons (Table 4).

\section{[INSERT TABLE 4 HERE]}

Also in bvFTD but not in $\mathrm{AD}$, ROI analyses uncovered significant associations between increased resting heart rate and cortical thinning in the mesial temporal cortex $(r=-.520, p=.002)$ and the insula $(r=-.490, p=.004)$. Additional correlations were also found with the prefrontal $(r=-.359, p=.04)$ and anterior cingulate cortices 
$(r=-.352, p=.04)$, again structures known to be integral to autonomic control, although these did not survive correction for multiple comparisons (Figure 54).

\section{[INSERT FIGURE $\underline{5} 4$ HERE]}

No further significant associations were found between stressed heart rate and cortical or subcortical regions in either bvFTD or AD.

Formatted: Centered 


\section{Discussion}

Behavioural variant frontotemporal dementia is characterized by an increased resting, stressed and sleeping heart rate compared to both $\mathrm{AD}$ and healthy controls. Given that changes in heart rate are indicative of changes in metabolic rate and energy expenditure (Berggren and Hohwu Christensen, 1950; Penzel et al., 2003), via the relationship between pulse rate, circulation and oxygen consumption, these changes suggest the presence of a hypermetabolic state in bvFTD. Behavioural variant frontotemporal dementia is also characterised by increased resting energy expenditure, total energy expenditure and decreased activity levels.-. Changes in heart rate correlate to a neural network involving the mesial temporal cortex, insula, nucleaus accumbens and cingulate.

In ALS, which overlaps clinically, pathologically and genetically with bvFTD, changes in heart rate (Chida et al., 1989) and a state of hypermetabolism (Desport et al., 2001) have also been documented, with an increased heart rate on formal autonomic function testing being found secondary to increased sympathetic and decreased parasympathetic input (Chida et al., 1989). In the present study, indications of decreased vagal tone and parasympathetic input in bvFTD were also present, with a trend towards decreased RMSSD, which is a measure of heart rate variability and reflects the integrity of vagus nerve mediated control of the heart (DeGiorgio et al., 2010). (Nonogaki, 2000; Messina et al., 2013)There is good experimental evidence in rodents and humans that changes in autonomic tone induced directly or indirectly (for example through thyroid disorders) affect energy expenditure and peripheral metabolism (lipolysis) (Nonogaki, 2000; Penicaud et al., 2000; Messina et al., 2013). It is therefore readily plausible that changes in heart rate may alter energy expenditure in patients with FTD. However, this remains to be established in studies using indirect calorimetry although we note these can be quite challenging in patients with complex behavioural problems.

Anecdotally, patients with bvFTD are described as being restless with pacing behaviour or alternatively to show inertia (Piguet et al., 2009), but activity levels have 
not been systematically examined. It has also been suggested that bvFTD patients may not show the degree of weight gain expected in the setting of their increased eating due to hyperactivity (Woolley et al., 2007). Here, however, we have demonstrated that bvFTD patients show decreased activity levels compared with $A D$ patients and healthy controls. This decreased activity may be secondary to the increased apathy seen in this disorder, which has been.r, related to atrophy in the right caudate, ventral striatum and cortical basal ganglia circuits (Eslinger et al., 2012), brain regions commonly affected in bvFTD.

In addition, bvFTD patients exhibited an increased resting energy expenditure (REE)REE, a measure of the resting metabolic rate, and total energy expenditure. The increased REE and basal metabolic state may in part be explained by the increased body mass index seen in the bvFTD group, but may also be influenced by the presence of a hypermetabolic state. This finding is in keeping with results in ALS

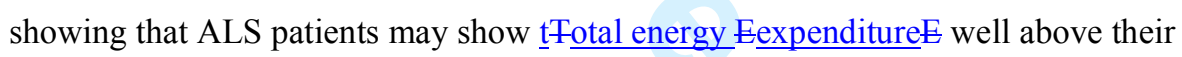
REE and activity levels and potentially secondary to hypermetabolism (Kasarskis et al., 2014).

Increased resting heart rate was also found to correlate with increasing cognitive impairment (lower ACE-III scores) and increasing behavioural impairment (higher CBI scores). Changes in neurodegeneration have been linked to alterations in energy homeostasis with animal models of ALS and FTD associated with weight loss and hypermetabolism (Dupuis et al., 2004; Chiang et al., 2010; Shan et al., 2010; Xu et al., 2010). Additional studies in patients with the language variants of FTD, particularly Semantic dementia may be informative. . It is suspected that there may well be changes in energy expenditure in semantic dementia given that they have similar changes in BMI to bvFTD in the contenxt of eating behavioural changes Formatted: Font: Not Italic
Formatted: Font: Not Italic
Formatted: Font: Not Italic, Not Highlight
Formatted: Font: Not Italic, Not Highlight
Formatted: Font: Not Italic (Ahmed et al 2014) and a similar pathology to ALS (TDP-43), where energy changes are prominent (Dupuis et al., 2011; Ahmed et al., 2016b).

It may be suggested that $\mp$ the changes seen in heart rate in bvFTD i.e. an increased resting and stressed and sleeping heart may be secondary to environmental factors $\underline{\text { such as caffeine, nicotine or alcohol consumption, rather than physiological changes. }}$ This seems unlikely given that there was no difference in reported smoking frequency 
and alcohol consumption between the groups, with only 2 bvFTD and 2 control subjects reported to be smokers, and similar rates of reported regular alcohol consumption, which were within recommended national guidelines. It is also unlikely that caffeine and tea intake would have affected the short term heart rate recordings (resting and stressed heart rate) as patients attended fasted and then received a breakfast with no caffeine available. Caffeine and tea intake was not measured during the long term measurements and this could potentially confound the long term recordings, however this is unlikely given that resting heart was elevated in the setting of the controlled environment of no caffeine consumption for the short term recordings. -When considering these results, it should be noted that changes in heart rate may potentially be related to decreased physical fitness associated with increasing disease severity, decreased activity secondary to apathy or loss of independence. However as increases in heart rate did not correlate with BMI changes, this suggests that changes in heart rate are far more complex than just being related to physical fitness and likely represent a complex interaction between atrophy in key cortical areas affecting autonomic function, and energy expenditure, and are likely to be centrally rather than peripherally mediated It is also unlikely that the changes in heart fate are simply related to decreased physical fitness associated with increasing disease severity, as increases in heart rate did not correlate with BMI changes, suggesting that ehanges in heart rate are far more complex and likely represent a complex interaction between atrophy in key cortical areas affecting autonomic function, and energy expenditure, and are likely to be centrally rather than peripherally mediated.

Whilst medications that potentially affect heart rate may affect the results of our $\underline{\text { study, there was no significant difference in use of chronotropic drugs between the }}$ groups. Cholinesterase inhibitor treatment has been linked with bradycardia in a small proportion of patients, (Hernandez et al., 2009). Despite the high number of AD patients on this medication, this is unlikely to be a confounding issue in the current study as the mean resting heart rate in the AD group was above that seen in the normal control population Medication usage that potentially affects heart rate is alse unlikely to be confounding the results as there was no significant difference in use of ehronotropic drugs between the groups. Cholinesterase inhibitor treatment has been linked with bradycardia in a small proportion of patients.(Hernandez et al., 2009 )

Formatted: Font: Not Italic Formatted: Font: Not Italic

Formatted: Font: Not Italic

Formatted: Font: Not Italic

Formatted: Font: Not Italic

Formatted: Font: Not Italic

Formatted: Font: Not Italic

Formatted: Font: Not Italic

Formatted: Font: Not Italic

Formatted: Font: Not Italic

Formatted: Font: Not Italic

Formatted: Font: Not Italic 
Despite the high number of $A D$ patients on this medication, this is unlikely to be a confounding issue in the current study as the mean resting heart rate in the AD group was above that seen in the normal control population.

(Hernandez et al., 2009)

In this study, an increased resting heart rate in bvFTD was found to correlate with atrophy of the mesial temporal cortex including hippocampus, together with the amygdala, nucleus accumbens, insula and cingulate, all structures known to be integral to autonomic control of the human body and involving the limbic system, which is known to be involved in FTD (Seeley et al., 2008; Jones, 2011). In bvFTD, pathological changes in these structures have traditionally being linked to disturbance of memory and social cognition (Galton et al., 2001; Kipps et al., 2009; Kumfor et al., 2013; Irish et al., 2014). Recently decreased cardiac vagal tone has been found in bvFTD and linked to reduced agreeableness and a network involving left-lateralized functional and structural frontoinsular and cingulate cortex deficits (Guo et al., 2016). Our findings suggest that in addition these structures may have a fundamental role in autonomic, energy expenditure and metabolic control in bvFTD.

The anterior cingulate cortex, has been shown to participate in decision making, response selection (Devinsky et al., 1995), anticipation of reward, task reinforcement (Amiez et al., 2006; Rushworth et al., 2007) and in controlling visceromotor, endocrine and skeletomotor outputs (Vogt et al., 1992), potentially via integration of cognitive with autonomic information (Critchley et al., 2001). In healthy individuals, activity of the anterior cingulate cortex has been associated with increased body mass index (Volkow et al., 2009) suggesting a role for this structure in regulating eating and metabolism. It has also been shown that the anterior cingulate cortex is related to sympathetic modulation of heart rate dissociable from cognitive and motor related activity and that focal damage to brain region can result in both an increase and decrease in heart rate (Critchley et al., 2003). Although the cingulate cortex responds to emotional stimuli, it is also metabolically active at rest (Raichle et al., 2001; Luu and Posner, 2003), suggesting a pivotal role for this brain region in the normal physiological control of the body.

Several studies and meta-analyses have shown the integral role that the amygdala plays in controlling heart and heart rate variability, particularly in times of emotional 
response and threat (Thayer et al., 2012). The fact that the amygdala correlated with increased resting heart rate in bvFTD in the current study, suggests that this structure plays a role in the physiological and metabolic changes seen in bvFTD and not simply in response to emotional stimuli. The insula is involved early in the course of bvFTD (Seeley et al., 2008) and has been found on voxel-based morphometry (VBM) to correlate to pain and temperature symptoms in bvFTD, with the suggestion that it forms a network hub for sensory homeostatic signalling with the thalamus in bvFTD. (Fletcher et al., 2015a). Our findings suggest that the insula also forms an important part of the network involved in heart rate, energy expenditure, autonomic and metabolic control in bvFTD

It is of interest that several of the structures found to correlate with increased resting heart rate namely the cingulate cortex, insula and amygdala have been found to correlate with hyperphagia and abnormal eating behaviour in bvFTD. Moreover all of these structures have connections to the hypothalamus (Kullmann et al., 2014; Ahmed et al., 2016a), which has been found to be atrophied in bvFTD and correlate with BMI measures (Ahmed et al., 2015b). This suggests a complex interaction between cortical, subcortical structures and the hypothalamus in the control of eating behaviour, heart rate and energy expenditure all of which are affected in bvFTD.

In $\mathrm{AD}$, by contrast, it has been speculated that weight loss occurs with disease progression and low body weight has previously being correlated to mesial temporal cortex atrophy (Grundman et al., 1996). Further studies are required using large samples documenting longitudinal weight loss and the neural correlates to ascertain the commonalities and differences controlling weight between FTD and $\triangle D$. Further studies using direct measurements of energy intake and expenditure in large numbers of patients and age-and BMI-matched controls (both normal and AD patients) longitudinally are required to assess the relative contributions of these parameters to weight changest gain in FTD. Further studies are required using large samples documenting longitudinal changes in weight, energy expenditure and eating behaviour, and the neural correlates to ascertain the commonalities and differences eontrolling weight between $\mathrm{FTD}$, and its variants, and $\Lambda \mathrm{D}$. It will also important to examine energy expenditure between the different forms of FTD (behavioural variant versus semantic dementia), given the differences in eating behaviour that are seen

\begin{tabular}{l} 
Formatted: Font: Not Italic \\
Formatted: Font: Not Italic \\
Formatted: Font: Not Italic \\
Formatted: Font: Not Italic \\
Formatted: Font: Not Italic \\
Formatted: Font: Not Italic \\
\hline
\end{tabular}

Formatted: Font: Not Italic, Not Highlight 
between these conditions (Ahmed et al., 2016a). It is suspected that there may well be ehanges in energy expenditure in semantic dementia given that they have similar ehanges in BMI to bvFTD, in the setting of eating behaviour change (Ahmed et al., 2014a) and a similar pathology (TDP 43) to ALS, where energy changes are prominent (Dupuis et al.,2004; Dupuis et al., 2011). Longitudinal studies will help to show the complex relationship between weight, eating behaviour and energy metabolism. (Ahmed et al., 2016a).

Behavioural variant frontotemporal dementia is characterized by an increased resting and sleeping heart rate indicative of changes in metabolic rate and resting energy expenditureREE which may moderate the weight gain in the setting of prominent changes of eating behaviour. BvFTD is also accompanied by decreased activity levels suggesting that energy expenditure changes are likely secondary to intrinsic processes, driven by changes in heart rate, rather than by an increase in activity levels. Changes in heart rate correlated with atrophy of cingulate and limbic systems including the insula and amygdala, which overlap with networks known to control eating behaviour in bvFTD. Further studies are required to document changes in heart rate and energy expenditure across the ALS-FTD spectrum and in presymptomatic genetic cohorts, to ascertain when changes first develop during the course of the disease. An approach combining longitudinal clinical studies and animal models of FTD and ALS will prove crucial. The current study is the first study to measure the interaction between heart rate, autonomic function and energy expenditure in FTD, using novelmethods from obesity research that allow for measurements over both $\underline{\text { short term and long term (7 days) in the patient's normal environment. Further studies }}$ $\underline{\text { using indirect calorimetry to measure basal metabolic rate and total energy }}$ expenditure are warranted to further examine these interactions. An understanding of the potential changes in energy expenditure, autonomic function and their neural correlates including involvement of the mesial temporal cortex, cingulate cortex, amygdala and insula in energy expenditure aids in the physiological phenotyping of FTD and extends our knowledge of the disease beyond cognition and emotion processing.
Formatted: Font: Not Italic, Not Highlight

Formatted: Font: Not Italic, Not Highlight

Formatted: Font: Not Italic, Not Highlight

Formatted: Font: Not Italic, Not Highlight

Formatted: Font: Not Italic, Not Highlight

Formatted: Font: Not Italic, Not Highlight

Formatted: Font: Not Italic, Not Highlight

Formatted: Font: Not Italic, Not Highlight

Formatted: Font: Not Italic, Not Highlight

Formatted: Font: Not Italic 
Funding: This work was supported by funding to Forefront, a collaborative research group dedicated to the study of frontotemporal dementia and motor neurone disease, from the National Health and Medical Research Council of Australia (NHMRC) program grant (\#1037746 to MK and JH) and the Australian Research Council Centre of Excellence in Cognition and its Disorders Memory Node (\#CE110001021 to OP and $\mathrm{JH}$ ) and other grants/sources (NHMRC project grant \#1003139). We are grateful to the research participants involved with the ForeFront research studies. RA is a Royal Australasian College of Physicians PhD scholar and MND Australia PhD scholar. OP is an NHMRC Career Development Research Fellow (\#1022684). ISF is supported by the Wellcome Trust, Medical Research Council, European Research Council, NIHR Cambridge Biomedical Research Centre and The Bernard Wolfe Endowment. AAvdK is supported by the Wellcome Trust. THC is supported by research grants from the Swiss National Science Foundation (PBLAP3-145870, P3SMP3-155318).

Author disclosures: The authors declare no competing financial interests

\section{Author contributions:}

Rebekah Ahmed: study concept, data analyses, manuscript preparation and writing. Ramon Landin--Romero: data analyses, manuscript preparation and writing. Tinh-Hai Collette: data analyses, manuscript preparation and writing. Agatha van der Klaauw: data analyses, manuscript preparation and writing Emma Devenney: data analyses, manuscript preparation and writing Elana Henning: data analyses, manuscript preparation and writing. Matthew C Kiernan: data analyses, manuscript preparation and writing. Olivier Piguet: data analyses, manuscript preparation and writing. Sadaf Farooqi: study concept, data analyses, manuscript preparation and writing. John Hodges: study concept, data analyses, manuscript preparation and writing.

Formatted: Font: (Default) Times New Roman Formatted: Font: (Default) Times New Roman Formatted: Font: (Default) Times New Roman Formatted: Font: (Default) Times New Roman Formatted: Font: (Default) Times New Roman Formatted: Font: (Default) Times New Roman Formatted: Font: (Default) Times New Roman Formatted: Font: (Default) Times New Roman 


\section{References}

Ahmed RM, Irish M, Kam J, van Keizerswaard J, Bartley L, Samaras K, Hodges JR, Piguet 0 . Quantifying the eating abnormalities in frontotemporal dementia. JAMA Neurol 2014a; 71: 1540-6.

Ahmed RM, MacMillan M, Bartley L, Halliday GM, Kiernan MC, Hodges JR, Piguet O. Systemic metabolism in frontotemporal dementia. Neurology 2014b; 83: $1812-8$.

Ahmed RM, Iodice V, Daveson N, Kiernan MC, Piguet O, Hodges JR. Autonomic dysregulation in frontotemporal dementia. J Neurol Neurosurg Psychiatry 2015a; 86: 1048-9.

Ahmed RM, Latheef S, Bartley L, Irish M, Halliday GM, Kiernan MC, Hodges JR, Piguet 0 . Eating behavior in frontotemporal dementia: Peripheral hormones vs hypothalamic pathology. Neurology 2015b; 85: 1310-7.

Ahmed RM, Irish M, Henning E, Dermody N, Bartley L, Kiernan MC, Piguet O, Farooqi S, Hodges JR. Assessment of Eating Behavior Disturbance and Associated Neural Networks in Frontotemporal Dementia. JAMA Neurol 2016a; 73: 282-90.

Ahmed RM, Irish M, Piguet O, Halliday GM, Ittner LM, Farooqi S, Hodges JR, Kiernan MC. Amyotrophic lateral sclerosis and frontotemporal dementia: distinct and overlapping changes in eating behaviour and metabolism. Lancet Neurol 2016b; 15: 332-42.

Amiez C, Joseph JP, Procyk E. Reward encoding in the monkey anterior cingulate cortex. Cereb Cortex 2006; 16: 1040-55.

Berggren G, Hohwu Christensen E. Heart rate and body temperature as indices of metabolic rate during work. Arbeitsphysiologie 1950; 14: 255-60.

Bouteloup C, Desport JC, Clavelou P, Guy N, Derumeaux-Burel H, Ferrier A, Couratier P. Hypermetabolism in ALS patients: an early and persistent phenomenon. J Neurol 2009; 256: 1236-42.

Bozeat S, Gregory CA, Ralph MA, Hodges JR. Which neuropsychiatric and behavioural features distinguish frontal and temporal variants of frontotemporal dementia from Alzheimer's disease? J Neurol Neurosurg Psychiatry 2000; 69: 178-86.

Brage S, Brage N, Franks PW, Ekelund U, Wong MY, Andersen LB, Froberg K, Wareham NJ. Branched equation modeling of simultaneous accelerometry and heart rate monitoring improves estimate of directly measured physical activity energy expenditure. J Appl Physiol (1985) 2004; 96: 34351.

Brage S, Brage N, Franks PW, Ekelund U, Wareham NJ. Reliability and validity of the combined heart rate and movement sensor Actiheart. Eur J Clin Nutr 2005; 59: 561-70.

Chiang PM, Ling J, Jeong YH, Price DL, Aja SM, Wong PC. Deletion of TDP-43 down-regulates Tbc1d1, a gene linked to obesity, and alters body fat metabolism. Proc Natl Acad Sci U S A 2010; 107: 16320-4.

Chida K, Sakamaki S, Takasu T. Alteration in autonomic function and cardiovascular regulation in amyotrophic lateral sclerosis. J Neurol 1989; 236: 127-30.

Critchley HD, Mathias CJ, Dolan RJ. Neural activity in the human brain relating to uncertainty and arousal during anticipation. Neuron 2001; 29: 537-45. 
Critchley HD, Mathias CJ, Josephs O, O'Doherty J, Zanini S, Dewar BK, Cipolotti L, Shallice T, Dolan RJ. Human cingulate cortex and autonomic control: converging neuroimaging and clinical evidence. Brain 2003; 126: 2139 52.

Crouter SE, Churilla JR, Bassett DR, Jr. Accuracy of the Actiheart for the assessment of energy expenditure in adults. Eur J Clin Nutr 2008; 62: 70411.

Dale AM, Fischl B, Sereno MI. Cortical surface-based analysis. I. Segmentation and surface reconstruction. Neuroimage 1999; 9: 179-94.

DeGiorgio CM, Miller P, Meymandi S, Chin A, Epps J, Gordon S, Gornbein J, Harper RM. RMSSD, a measure of vagus-mediated heart rate variability, is associated with risk factors for SUDEP: the SUDEP-7 Inventory. Epilepsy Behav 2010; 19: 78-81.

Desport JC, Preux PM, Magy L, Boirie Y, Vallat JM, Beaufrere B, Couratier P. Factors correlated with hypermetabolism in patients with amyotrophic lateral sclerosis. Am J Clin Nutr 2001; 74: 328-34.

Devinsky O, Morrell MJ, Vogt BA. Contributions of anterior cingulate cortex to behaviour. Brain 1995; 118 ( Pt 1): 279-306.

Dupuis L, Oudart H, Rene F, Gonzalez de Aguilar JL, Loeffler JP. Evidence for defective energy homeostasis in amyotrophic lateral sclerosis: benefit of a high-energy diet in a transgenic mouse model. Proc Natl Acad Sci U S A 2004; 101: 11159-64.

Dupuis L, Pradat PF, Ludolph AC, Loeffler JP. Energy metabolism in amyotrophic lateral sclerosis. Lancet Neurol 2011; 10: 75-82.

Eslinger PJ, Moore P, Antani S, Anderson C, Grossman M. Apathy in frontotemporal dementia: behavioral and neuroimaging correlates. Behav Neurol 2012; 25: 127-36.

Fischl B, Sereno MI, Dale AM. Cortical surface-based analysis. II: Inflation, flattening, and a surface-based coordinate system. Neuroimage 1999; 9: 195-207.

Fischl B, Dale AM. Measuring the thickness of the human cerebral cortex from magnetic resonance images. Proc Natl Acad Sci U S A 2000; 97: 11050-5.

Fletcher PD, Downey LE, Golden HL, Clark CN, Slattery CF, Paterson RW, Rohrer JD, Schott JM, Rossor MN, Warren JD. Pain and temperature processing in dementia: a clinical and neuroanatomical analysis. Brain 2015a; 138: 3360-72.

Fletcher PD, Nicholas JM, Shakespeare TJ, Downey LE, Golden HL, Agustus JL, Clark CN, Mummery CJ, Schott JM, Crutch SJ, Warren JD. Physiological phenotyping of dementias using emotional sounds. Alzheimers Dement (Amst) 2015b; 1: 170-178.

Galton CJ, Gomez-Anson B, Antoun N, Scheltens P, Patterson K, Graves M, Sahakian BJ, Hodges JR. Temporal lobe rating scale: application to Alzheimer's disease and frontotemporal dementia. J Neurol Neurosurg Psychiatry 2001; 70: 165-73.

Gorno-Tempini ML, Hillis AE, Weintraub S, Kertesz A, Mendez M, Cappa SF, Ogar JM, Rohrer JD, Black S, Boeve BF, Manes F, Dronkers NF, Vandenberghe R, Rascovsky K, Patterson K, Miller BL, Knopman DS, Hodges JR, Mesulam $\mathrm{MM}$, Grossman M. Classification of primary progressive aphasia and its variants. Neurology 2011; 76: 1006-14. 
Grundman M, Corey-Bloom J, Jernigan T, Archibald S, Thal LJ. Low body weight in Alzheimer's disease is associated with mesial temporal cortex atrophy. Neurology 1996; 46: 1585-91.

Guo CC, Sturm VE, Zhou J, Gennatas ED, Trujillo AJ, Hua AY, Crawford R, Stables L, Kramer JH, Rankin K, Levenson RW, Rosen HJ, Miller BL, Seeley WW. Dominant hemisphere lateralization of cortical parasympathetic control as revealed by frontotemporal dementia. Proc Natl Acad Sci U S A 2016.

Hernandez RK, Farwell W, Cantor MD, Lawler EV. Cholinesterase inhibitors and incidence of bradycardia in patients with dementia in the veterans affairs new England healthcare system. J Am Geriatr Soc 2009; 57: 1997-2003.

Hsieh S, Schubert S, Hoon C, Mioshi E, Hodges JR. Validation of the Addenbrooke's Cognitive Examination III in frontotemporal dementia and Alzheimer's disease. Dement Geriatr Cogn Disord 2013; 36: 242-50.

Ikeda M, Brown J, Holland AJ, Fukuhara R, Hodges JR. Changes in appetite, food preference, and eating habits in frontotemporal dementia and Alzheimer's disease. J Neurol Neurosurg Psychiatry 2002; 73: 371-6.

Irish M, Piguet O, Hodges JR, Hornberger M. Common and unique gray matter correlates of episodic memory dysfunction in frontotemporal dementia and Alzheimer's disease. Hum Brain Mapp 2014; 35: 1422-35.

Jones SE. Imaging for autonomic dysfunction. Cleve Clin J Med 2011; 78 Suppl 1: S69-74.

Kasarskis EJ, Mendiondo MS, Matthews DE, Mitsumoto H, Tandan R, Simmons Z, Bromberg MB, Kryscio RJ, Group ALSNNS. Estimating daily energy expenditure in individuals with amyotrophic lateral sclerosis. Am J Clin Nutr 2014; 99: 792-803.

Kipps CM, Nestor PJ, Acosta-Cabronero J, Arnold R, Hodges JR. Understanding social dysfunction in the behavioural variant of frontotemporal dementia: the role of emotion and sarcasm processing. Brain 2009; 132: 592-603.

Koppers M, Blokhuis AM, Westeneng HJ, Terpstra ML, Zundel CA, Vieira de Sa R, Schellevis RD, Waite AJ, Blake DJ, Veldink JH, van den Berg LH, Pasterkamp RJ. C9orf72 ablation in mice does not cause motor neuron degeneration or motor deficits. Ann Neurol 2015; 78: 426-38.

Kullmann S, Heni M, Linder K, Zipfel S, Haring HU, Veit R, Fritsche A, Preissl H. Resting-state functional connectivity of the human hypothalamus. Hum Brain Mapp 2014; 35: 6088-96.

Kumfor F, Irish M, Hodges JR, Piguet 0. Discrete Neural Correlates for the Recognition of Negative Emotions: Insights from Frontotemporal Dementia. PLoS One 2013; 8: e67457.

Lerch JP, Evans AC. Cortical thickness analysis examined through power analysis and a population simulation. Neuroimage 2005; 24: 163-73.

Lieberman MD, Cunningham WA. Type I and Type II error concerns in fMRI research: re-balancing the scale. Soc Cogn Affect Neurosci 2009; 4: 423-8.

Luu P, Posner MI. Anterior cingulate cortex regulation of sympathetic activity. Brain 2003; 126: 2119-20.

McKhann GM, Albert MS, Grossman M, Miller B, Dickson D, Trojanowski JQ, Work Group on Frontotemporal D, Pick's D. Clinical and pathological diagnosis of frontotemporal dementia: report of the Work Group on Frontotemporal Dementia and Pick's Disease. Arch Neurol 2001; 58: 1803-9. 
McKhann GM, Knopman DS, Chertkow H, Hyman BT, Jack CR, Jr., Kawas CH, Klunk WE, Koroshetz WJ, Manly JJ, Mayeux R, Mohs RC, Morris JC, Rossor MN, Scheltens P, Carrillo MC, Thies B, Weintraub S, Phelps CH. The diagnosis of dementia due to Alzheimer's disease: recommendations from the National Institute on Aging-Alzheimer's Association workgroups on diagnostic guidelines for Alzheimer's disease. Alzheimers Dement 2011; 7: 263-9.

Messina G, De Luca V, Viggiano A, Ascione A, Iannaccone T, Chieffi S, Monda M. Autonomic nervous system in the control of energy balance and body weight: personal contributions. Neurol Res Int 2013; 2013: 639280.

Mioshi E, Hsieh S, Savage S, Hornberger M, Hodges JR. Clinical staging and disease progression in frontotemporal dementia. Neurology 2010; 74: 1591-7.

Morris JC. The Clinical Dementia Rating (CDR): current version and scoring rules. Neurology 1993; 43: 2412-4.

Nonogaki K. New insights into sympathetic regulation of glucose and fat metabolism. Diabetologia 2000; 43: 533-49.

Pearce LR, Atanassova N, Banton MC, Bottomley B, van der Klaauw AA, Revelli JP, Hendricks A, Keogh JM, Henning E, Doree D, Jeter-Jones S, Garg S, Bochukova EG, Bounds R, Ashford S, Gayton E, Hindmarsh PC, Shield JP, Crowne E, Barford D, Wareham NJ, consortium UK, O'Rahilly S, Murphy MP, Powell DR, Barroso I, Farooqi IS. KSR2 mutations are associated with obesity, insulin resistance, and impaired cellular fuel oxidation. Cell 2013; 155: 765-77.

Penicaud L, Cousin B, Leloup C, Lorsignol A, Casteilla L. The autonomic nervous system, adipose tissue plasticity, and energy balance. Nutrition 2000; 16: 903-8.

Penzel T, Kantelhardt JW, Lo CC, Voigt K, Vogelmeier C. Dynamics of heart rate and sleep stages in normals and patients with sleep apnea. Neuropsychopharmacology 2003; 28 Suppl 1: S48-53.

Piguet O, Hornberger M, Shelley BP, Kipps CM, Hodges JR. Sensitivity of current criteria for the diagnosis of behavioral variant frontotemporal dementia. Neurology 2009; 72: 732-7.

Raichle ME, MacLeod AM, Snyder AZ, Powers WJ, Gusnard DA, Shulman GL. A default mode of brain function. Proc Natl Acad Sci U S A 2001; 98: 676-82.

Rascovsky K, Hodges JR, Knopman D, Mendez MF, Kramer JH, Neuhaus J, van Swieten JC, Seelaar H, Dopper EG, Onyike CU, Hillis AE, Josephs KA, Boeve BF, Kertesz A, Seeley WW, Rankin KP, Johnson JK, Gorno-Tempini ML, Rosen H, Prioleau-Latham CE, Lee A, Kipps CM, Lillo P, Piguet O, Rohrer JD, Rossor MN, Warren JD, Fox NC, Galasko D, Salmon DP, Black SE, Mesulam M, Weintraub S, Dickerson BC, Diehl-Schmid J, Pasquier F, Deramecourt V, Lebert F, Pijnenburg Y, Chow TW, Manes F, Grafman J, Cappa SF, Freedman M, Grossman M, Miller BL. Sensitivity of revised diagnostic criteria for the behavioural variant of frontotemporal dementia. Brain 2011; 134: 2456-77.

Rushworth MF, Behrens TE, Rudebeck PH, Walton ME. Contrasting roles for cingulate and orbitofrontal cortex in decisions and social behaviour. Trends Cogn Sci 2007; 11: 168-76. 
Schofield WN. Predicting basal metabolic rate, new standards and review of previous work. Hum Nutr Clin Nutr 1985; 39 Suppl 1: 5-41.

Seeley WW, Crawford R, Rascovsky K, Kramer JH, Weiner M, Miller BL, GornoTempini ML. Frontal paralimbic network atrophy in very mild behavioral variant frontotemporal dementia. Arch Neurol 2008; 65: 249-55.

Shan X, Chiang PM, Price DL, Wong PC. Altered distributions of Gemini of coiled bodies and mitochondria in motor neurons of TDP-43 transgenic mice. Proc Natl Acad Sci U S A 2010; 107: 16325-30.

Tarvainen MP, Niskanen JP, Lipponen JA, Ranta-Aho PO, Karjalainen PA. Kubios HRV--heart rate variability analysis software. Comput Methods Programs Biomed 2014; 113: 210-20.

Thayer JF, Ahs F, Fredrikson M, Sollers JJ, 3rd, Wager TD. A meta-analysis of heart rate variability and neuroimaging studies: implications for heart rate variability as a marker of stress and health. Neurosci Biobehav Rev 2012; 36: 747-56.

Vaisman N, Lusaus M, Nefussy B, Niv E, Comaneshter D, Hallack R, Drory VE. Do patients with amyotrophic lateral sclerosis (ALS) have increased energy needs? J Neurol Sci 2009; 279: 26-9.

Voevodskaya O, Simmons A, Nordenskjold R, Kullberg J, Ahlstrom H, Lind L, Wahlund LO, Larsson EM, Westman E, Alzheimer's Disease Neuroimaging I. The effects of intracranial volume adjustment approaches on multiple regional MRI volumes in healthy aging and Alzheimer's disease. Front Aging Neurosci 2014; 6: 264.

Vogt BA, Finch DM, Olson CR. Functional heterogeneity in cingulate cortex: the anterior executive and posterior evaluative regions. Cereb Cortex 1992; 2: 435-43.

Volkow ND, Wang GJ, Telang F, Fowler JS, Goldstein RZ, Alia-Klein N, Logan J, Wong C, Thanos PK, Ma Y, Pradhan K. Inverse association between BMI and prefrontal metabolic activity in healthy adults. Obesity (Silver Spring) 2009; 17: 60-5.

Woolley JD, Gorno-Tempini ML, Seeley WW, Rankin K, Lee SS, Matthews BR, Miller BL. Binge eating is associated with right orbitofrontal-insularstriatal atrophy in frontotemporal dementia. Neurology 2007; 69: 142433.

Xu YF, Gendron TF, Zhang YJ, Lin WL, D'Alton S, Sheng H, Casey MC, Tong J, Knight J, Yu X, Rademakers R, Boylan K, Hutton M, McGowan E, Dickson DW, Lewis J, Petrucelli L. Wild-type human TDP-43 expression causes TDP-43 phosphorylation, mitochondrial aggregation, motor deficits, and early mortality in transgenic mice. J Neurosci 2010; 30: 10851-9. 


\section{Figure Legends}

Figure 1: Scatter plot showing BMI values in bvFTD, AD and healthy controls

Horizontal line represents mean $+/-\mathrm{SD}$, bvFTD $>\mathrm{AD}$ and controls $(\mathrm{p}<.001)$

Formatted: Font: Bold

Formatted: Font: Not Bold

Formatted: Font: Not Bold

Figure 21. Resting and stressed heart rate in bvFTD, AD and healthy controls

$* \operatorname{bvFTD}>\operatorname{AD}(p=.028), * *$ bvFTD $>$ Controls $(p=.037), * * *$ bvFTD $>$ Controls $(p=$ $.001)$

\section{Figure $\underline{3} z$. Long term Actiheart results}

A) Mean sleeping heart rate. $* * *$ bvFTD $>$ controls $(\mathrm{p}=.038)$; B) Mean activity counts per 24 hours. * $\underline{\mathrm{AD}<\text { Controlsb }} \mathrm{FTD}, \mathrm{AD}(p=.05), * *$ bvFTD $<$ Controls $(p=.002)$

Figure 43. Regions showing significant correlations between cortical thinning and increasing resting heart rate in bvFTD and AD in whole brain imaging analyses. Statistical significance was set at $\mathrm{p}<.001$ uncorrected for multiple comparisons. bvFTD = behavioural-variant frontotemporal dementia; $\mathrm{AD}=$ Alzheimer's disease

Figure 54. Significant associations between cortical thickness in preselected ROIs and resting heart rate in bvFTD and HC. No significant associations were seen in AD and HC. Statistical significance was set at $\mathrm{p}<.0125$ Bonferroni corrected for multiple comparisons. bvFTD = behavioural-variant frontotemporal dementia; $\mathrm{HC}=$ Healthy controls

Supplementary Figure S1. Patterns of atrophy in bvFTD and AD versus healthy controls. Blue coloured regions show significant cortical thinning in the patient groups compared to controls ( $p<.05$ FDR corrected). Red coloured regions show significantly increased cortical thickness in the patient group compared to controls $(\mathrm{p}$ $<.05$ FDR corrected). 
Table 1. Demographics and clinical characteristics in bvFTD, AD and healthy controls

Formatted: Font: Bold

Formatted Table

\begin{tabular}{|c|c|c|c|c|c|c|}
\hline & $\begin{array}{l}\text { bvFTD } \\
(n=19)\end{array}$ & $\begin{array}{c}\text { AD } \\
(n=13)\end{array}$ & $\begin{array}{c}\text { HC } \\
(n=16)\end{array}$ & F value & $p$ value & Post hoc \\
\hline $\operatorname{Sex}(F: M)$ & $8: 11$ & $7: 6$ & $6: 10$ & $.83^{\dagger}$ & ns & - \\
\hline Age (years) & $62 \pm 6.7$ & $66 \pm 8.2$ & $65 \pm 7.7$ & 1.1 & ns & - \\
\hline BMI $\left(\mathrm{kg} / \mathrm{m}^{2}\right)$ & $31.0 \pm 6.9$ & $23.6 \pm 3.1$ & $27.2 \pm 5.9$ & 9.6 & $p<.001$ & bvFTD $>$ AD, HC \\
\hline ACE-III Total (max 100) & $67.1 \pm 20.7$ & $64.3 \pm 11.2$ & $95.1 \pm 1.9$ & 21.6 & $p<.001$ & $\mathrm{HC}>$ patients \\
\hline Disease duration (years) & $3.5 \pm 1.9$ & $4.7 \pm 4.5$ & - & $.972 \#$ & ns & - \\
\hline FRS Rasch score ${ }^{\wedge}$ & $-1.7 \pm 1.2$ & $-.02 \pm 1.4$ & - & $17.7 \#$ & $p<.01$ & bvFTD $<$ AD \\
\hline APEHQ Total & $68.9 \pm 38.6$ & $15.1 \pm 20.2$ & - & $4.1 \#$ & $p<.001$ & bvFTD $>$ AD \\
\hline CBI Total & $86.3 \pm 24.7$ & $51.3 \pm 27.3$ & - & $3.6 \#$ & $p<.01$ & bvFTD $>$ AD \\
\hline CBI eating Total & $9.3 \pm 3.8$ & $3.2 \pm 4.5$ & - & $4.1 \#$ & $p<.001$ & bvFTD $>$ AD \\
\hline Number-Treatmented with & $\underline{2}$ & $\underline{9}$ & $\underline{0}$ & $\underline{22.2^{\dagger}}$ & $p<.001$ & $\underline{\mathrm{AD}}>$ bvFTD and $\mathrm{HC}$ \\
\hline \multicolumn{7}{|l|}{ cholinesterase inhibitor (n) } \\
\hline Number tTreatmented with & $\underline{2}$ & $\underline{1}$ & $\underline{1}$ & $\underline{.21^{\dagger}}$ & $\underline{\mathrm{ns}}$ & 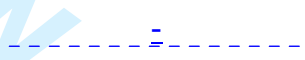 \\
\hline \multicolumn{7}{|l|}{$\underline{\text { Beta-blocker or calcium }}$} \\
\hline \multicolumn{7}{|l|}{ channel blocker (n) } \\
\hline Current Ssmokers (n) & $\underline{2}$ & $\underline{0}$ & $\underline{2}$ & $\underline{1.7^{\dagger}}$ & $\underline{\mathrm{nS}}$ & $=$ \\
\hline Alcohol consumption (n) & $\underline{8}$ & $\underline{5}$ & $\underline{10}$ & $\underline{2.1^{\dagger}}$ & $\underline{\mathrm{ns}}$ & $=$ \\
\hline
\end{tabular}

Formatted: Font: Not Italic

Formatted: Font: $12 \mathrm{pt}$, Not Italic, Font color: Text 1 
Values are expressed as mean \pm standard deviation. bvFTD $=$ behavioural-variant frontotemporal dementia; $\mathrm{AD}=\mathrm{Alzheimer}$ 's disease; $\mathrm{HC}=$ healthy controls; BMI = body mass index; ACE-III = Addenbrooke's Cognitive Examination-III; FRS = Frontotemporal dementia Rating Scale; $\mathrm{APEHQ}=$ Appetite and Eating Habits Questionnaire; $\mathrm{CBI}=$ Cambridge Behavioural Inventory; ns = not significant. ${ }^{\dagger} \mathrm{Chi}$-square test; \# t-value; ${ }^{\wedge}$ The FRS provides logit scores ranging from 4.12 (very mild) to -4.99 (very severe). $\mathrm{N}=$ number of patients normally reporting alcohol and regular smokers. All alcohol consumption was within normal guidelines (see text). 
Table 2. Measures of heart rate variability and autonomic function

\begin{tabular}{|c|c|c|c|c|c|}
\hline & $\begin{array}{l}\text { bvFTD } \\
(n=19)\end{array}$ & $\begin{array}{c}\text { AD } \\
(n=13)\end{array}$ & $\begin{array}{c}\text { HC } \\
(n=16)\end{array}$ & F value & $p$ value \\
\hline Resting LF & $.06 \pm .02$ & $.07 \pm .02$ & $.06 \pm .01$ & .38 & ns \\
\hline Resting HF & $.20 \pm .08$ & $.20 \pm .07$ & $.26 \pm .07$ & 2.6 & ns \\
\hline Resting RMSSD & $21.7 \pm 11.1$ & $29.2 \pm 18.6$ & $41.7 \pm 35.1$ & 2.7 & ns \\
\hline Stressed LF & $.08 \pm .10$ & $.07 \pm .02$ & $.07 \pm .03$ & .10 & ns \\
\hline Stressed HF & $.21 \pm .07$ & $.22 \pm .09$ & $.22 \pm .07$ & .08 & ns \\
\hline Stressed RMSSD & $23.3 \pm 15.3$ & $31.6 \pm 17.9$ & $41.7 \pm 31.9$ & 2.9 & ns \\
\hline Rested LF/HF & $.34 \pm .10$ & $35 \pm .20$ & $.29 \pm .14$ & 1.7 & ns \\
\hline Stressed LF/HF & $.48 \pm .65$ & $.38 \pm .17$ & $.37 \pm .15$ & 1.8 & ns \\
\hline
\end{tabular}

Values are expressed as mean \pm standard deviation. Statistical analyses performed on Log transformed values. bvFTD $=$ behavioural-variant

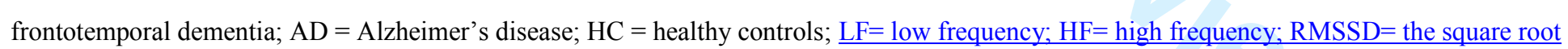
of the mean squared difference of successive beat to beat intervals and a measure of vagal control of the heart 
Table 3. Average energy expenditure (kcal) per day in bvFTD, AD and healthy controls

\begin{tabular}{|c|c|c|c|c|c|c|}
\hline & bvFTD $^{\mathrm{a}}$ & $\mathbf{A D}^{\mathbf{a}}$ & $\mathrm{HC}^{\mathrm{a}}$ & F value & $p$ value & Post hoc \\
\hline Resting energy & $1656.9 \pm 245.0$ & $1356.4 \pm 170.5$ & $1442.1 \pm 173.7$ & 6.4 & .005 & bvFTD $>\mathrm{HC}(p=.045)$ \\
\hline expenditureEE & & & & & & $\mathrm{bvFTD}>\mathrm{AD}(p=.005)$ \\
\hline $\begin{array}{l}\text { Active energy } \\
\text { expenditureEE }\end{array}$ & $676.9 \pm 428.3$ & $471.1 \pm 278.8$ & $525.1 \pm 141.1$ & 1.3 & .291 & - \\
\hline $\begin{array}{l}\text { Diet induced } \\
\text { thermogenesisfF }\end{array}$ & $259.2 \pm 53.6$ & $202.9 \pm 43.9$ & $218.3 \pm 24.6$ & 5.0 & .013 & $\begin{array}{l}\text { bvFTD }>\operatorname{HC}(p=.035) \\
\text { bvFTD }>\operatorname{AD}(p=.013)\end{array}$ \\
\hline Total energy & $2592.4 \pm 533.9$ & $2028.5 \pm 440.9$ & $2182 \pm 246.4$ & 5.0 & .013 & bvFTD $>\mathrm{HC}(p=.035)$ \\
\hline expenditureEE & & & & & & bvFTD $>\operatorname{AD}(p=.013)$ \\
\hline $\begin{array}{l}\text { Physical activity } \\
\text { levelAL }\end{array}$ & $1.6 \pm .3$ & $1.5 \pm .1$ & $1.5 \pm .1$ & .6 & .531 & - \\
\hline
\end{tabular}

Values are expressed as mean \pm standard deviation. bvFTD $=$ behavioural-variant frontotemporal dementia; $\mathrm{AD}=\mathrm{Alzheimer}$ 's disease; $\mathrm{HC}=$

healthy controls; REE = Resting Energy Expenditure; AEE = Activity Energy Expenditure; DIT = Dietary Induced Thermogenesis; TEE = Total

Energy Expenditure; PAL = Physical activity level. ${ }^{a}$ Missing data: Data missing for 7 bvFTD, 3 AD and 5 HC.
Formatted: Font: Bold 
Table 4. Correlations between subcortical volumes and resting heart rate in bvFTD and AD

\begin{tabular}{lccccccc}
\hline & Thalamus & Caudate & Putamen & Pallidum & Hippocampus & Amygdala & Accumbens \\
\hline bvFTD & $-.349^{*}$ & -.334 & $-.342^{*}$ & -.197 & $\mathbf{- . 5 2 9 * *}$ & $-.352^{*}$ & $-.446^{*}$ \\
AD & .031 & .173 & .159 & .257 & .056 & -.004 & .026 \\
\hline
\end{tabular}

Values as expressed in Pearson's correlation coefficient scores. * Denotes that the correlation is significant at the 0.05 level. $* *$ Denotes that the correlation is significant at the 0.01 level. Significant correlations after correction for multiple comparisons are highlighted in bold. bvFTD $=$ behavioural-variant frontotemporal dementia; $\mathrm{AD}=$ Alzheimer's disease. Statistical significance was set at $\mathrm{p}<.007$ Bonferroni corrected for multiple comparisons. 